\title{
A small multigene hydroxyproline-O- galactosyltransferase family functions in arabinogalactan-protein glycosylation, growth and development in Arabidopsis
}

Debarati Basu, Lu Tian, Wuda Wang, Shauni Bobbs, Hayley Herock, Andrew Travers and Allan M. Showalter

\begin{abstract}
Background: Arabinogalactan-proteins (AGPs) are ubiquitous components of cell walls throughout the plant kingdom and are extensively post translationally modified by conversion of proline to hydroxyproline (Hyp) and by addition of arabinogalactan polysaccharides (AG) to Hyp residues. AGPs are implicated to function in various aspects of plant growth and development, but the functional contributions of AGP glycans remain to be elucidated. Hyp glycosylation is initiated by the action of a set of Hyp-O-galactosyltransferase (Hyp-O-GALT) enzymes that remain to be fully characterized.

Results: Three members of the GT31 family (GALT3-At3g06440, GALT4-At1g27120, and GALT6-At5g62620) were identified as Hyp-O-GALT genes by heterologous expression in tobacco leaf epidermal cells and examined along with two previously characterized Hyp-O-GALT genes, GALT2 and GALT5. Transcript profiling by real-time PCR of these five Hyp-O-GALTs revealed overlapping but distinct expression patterns. Transiently expressed GALT3, GALT4 and GALT6 fluorescent protein fusions were localized within Golgi vesicles. Biochemical analysis of knock-out mutants for the five Hyp-O-GALT genes revealed significant reductions in both AGP-specific Hyp-O-GALT activity and $\beta$-Gal-Yariv precipitable AGPs. Further phenotypic analysis of these mutants demonstrated reduced root hair growth, reduced seed coat mucilage, reduced seed set, and accelerated leaf senescence. The mutants also displayed several conditional phenotypes, including impaired root growth, and defective anisotropic growth of root tips under salt stress, as well as less sensitivity to the growth inhibitory effects of $\beta$-Gal-Yariv reagent in roots and pollen tubes.
\end{abstract}

Conclusions: This study provides evidence that all five Hyp-O-GALT genes encode enzymes that catalyze the initial steps of AGP galactosylation and that AGP glycans play essential roles in both vegetative and reproductive plant growth.

Keywords: Arabidopsis, Arabinogalactan-proteins, AGP biosynthesis, Galactosyltransferase, O-glycosylation, Plant cell wall, Hydroxyproline, Galactose

\footnotetext{
* Correspondence: showalte@ohio.edu

Molecular and Cellular Biology Program, Department of Environmental and

Plant Biology, Ohio University, Athens, OH 45701-2979, USA
} 


\section{Background}

Arabinogalactan-proteins (AGPs) are members of the hydroxyproline (Hyp)-rich cell wall glycoprotein superfamily and are hyperglycosylated by $O$-linked AG polysaccharides. AGPs are found in cell walls, plasma membranes, and extracellular secretions of virtually all plant cells, tissues and organ types [1]. Moderately sized gene families encode a variety of AGP protein backbones throughout the plant kingdom. For example, based on bioinformatics studies, Arabidopsis contains 85 AGP genes, while rice contains 69 AGP genes $[2,3]$. Moreover, these genes are spatially and temporally expressed in a variety of patterns, which likely relates to their multiple functions.

AGPs are implicated to function in various aspects of plant growth and development, including root elongation, somatic embryogenesis, hormone responses, xylem differentiation, pollen tube growth and guidance, programmed cell death, cell expansion, salt tolerance, host-pathogen interactions, and cellular signaling [4-10]. However, there remains a lack of understanding of the biophysical and biochemical modes of action of any individual AGP. This lack of understanding regarding function also extends to the carbohydrate moieties or AG polysaccharides, which extensively decorate AGP core proteins and largely define their interactive surfaces.

Given the importance of understanding plant cell wall biosynthesis particularly with respect to biofuel production, much of the recent work on AGPs has focused on their biosynthesis. Such efforts have identified several of the biosynthetic glycosyltransferase (GT) genes/enzymes responsible for AG polysaccharide production $[6,11]$. In particular, the following enzymes were identified and cloned: two $\alpha$-1,2-fucosyltransferases (FUT4 and FUT6) which are members of the CAZy GT-37 family [12-14], two hydroxyproline-O-galactosyltransferases (GALT2 and GALT5) which are members of GT-31 and contain a galectin domain $[15,16]$, three other hydroxyproline-Ogalactosyltransferases (HPGT1-HPGT3) which are members of GT-31 but lack a galectin domain [17], one $\beta-1,3-$ galactosyltransferase (At1g77810) which is a member of GT-31 [18], one $\beta$-1,6-galactosyltransferase with elongation activity which is a member of GT-31 (GALT31A) [19], one $\beta-1,6$-galactosyltransferase with branch initiation and branch elongating activities which is a member of GT-29 (GALT29A) [20], three $\beta$-1,6-gluronosyltransferases which are members of GT-14 (GlcAT14A, GlcAT14B, GlcAT14C) [21, 22], and a putative AGP $\beta$-arabinosyltransferase (RAY1) which is a member of the GT-77 family [23].

The hydroxyproline-O-galactosyltransferases (Hyp-OGALT) that add galactose onto the peptidyl Hyp residues in AGP core proteins represent the first committed step in AG polysaccharide addition and represent an ideal control point to investigate the contribution of AG polysaccharides to AGP function. Previously, we demonstrated that GALT2 (At4g21060) and GALT5 (At1g74800) are members of a small multigene family and encode Hyp-GALTs [15, 16]. In addition, extensive phenotypic characterization of allelic galt 2 and galt 5 single mutants and galt2galt 5 double mutants at the biochemical and physiological levels was performed which corroborated the roles of these two enzymes in AG biosynthesis and elucidated the contributions of AG polysaccharides to AGP function. Here, we extend that work by characterizing the remaining GALT members (i.e., GALT1, GALT3, GALT4, and GALT6) of this small six-membered gene family, which are distinguished by encoding a GALT domain as well as a GALECTIN domain.

\section{Results}

In silico analysis of GALT1, GALT3, GALT4, and GALT6

This study focused on the six-member gene/protein family in Arabidopsis, which is found within the CAZy GT31 family and distinguished by the presence of both a GALT (pfam 01762) and a GALECTIN (pfam 00337) domain. Recently, two of these six members, GALT2 (At4g21060) and GALT5 (At1g74800) were demonstrated to catalyze the addition of galactose onto Hyp residues of AGP backbones $[15,16]$. Another member of this family, GALT1, encoded by At1g26810, was previously characterized and identified as a $\beta-1,3$-galactosyltransferase involved in the formation of the Lewis a epitope on $N$-linked glycans [24]. The open reading frames of the remaining members, At3g06440 (GALT3), At1g27120 (GALT4), and At5g62620 (GALT6) correspond to 1860,2022 and 2046 bp and specify proteins with 619 $(70 \mathrm{kDa}), 673(77.0 \mathrm{kDa})$, and $681(77.7 \mathrm{kDa})$ amino acids, respectively (Additional file 1: Table S1). The six proteins share amino acid identities ranging from 35 to $70 \%$ (Additional file 1: Table S2). In addition, comparisons of these six members were performed with the three recently identified AGP-specific Hyp-O-GALTs (HPGT1, HPGT2, and HPGT3), which are also within the GT31 family and contain a GALT domain but lack a GALECTIN domain [17]. All nine proteins were predicted to be type II Golgi localized integral membrane proteins by several subcellular localization prediction programs (TargetP, http://www.cbs.dtu.dk/services/TargetP/ and Golgi Predictor, http://ccb.imb.uq.edu.au/golgi/) [25], Additional file 1: Table S2). These nine GALTs were also submitted the TMHMM server (http://www.cbs.dtu.dk/services/ TMHMM/) for prediction of transmembrane domains (TMDs), a typical type II membrane topology commonly found in GTs [26] (Additional file 1: Figure S1). All were predicted to have a single TMD except for GALT3, HPGT2, and HPGT3, which instead contained hydrophobic regions that may serve as an anchor to the Golgi 
membrane. Hydrophobic cluster analysis (HCA) was performed by submitting the protein sequences to the drawhca server (http://bioserv.impmc.jussieu.fr/hcaform.html) and used to identify the hydrophobic pockets containing the "DXD" motifs of the six GALTs; this analysis also included two previously characterized AGPrelated GT31 members, GALT31A and At1g77810, which are involved with the elongation of $\beta$-1,6-galactan side chains and the $\beta-1,3$ backbone of AG polysaccharides, respectively (Additional file 1: Figure S2) [18, 19, 27, 28]. HCA analysis revealed conserved DDD motifs in all the proteins contained within various hydrophobic pockets. The DXD motif is implicated in the binding the divalent metal ion that assists in anchoring the pyrophosphoryl group of the UDP-sugar donor in the enzyme's active site [18]. Co-expression analysis was performed using GENEMANIA (http://www.genemania.org/) and revealed that GALT3, GALT4, and GALT6 expression is tightly correlated with well-characterized AGP-specific GT31 members as well as with a number of AGPs (Additional file 1: Table S3) [15, 18, 19, 24, 29].

\section{Transiently expressed GALT genes in Nicotiana have AGP-specific Hyp-O-GALT activity}

For biochemical characterization, full-length GALT1, GALT2, GALT3, GALT4, GALT5, and GALT6 gene constructions, each harboring an N-terminal 6XHis tag, were transiently expressed in the leaves of Nicotiana tabacum. Leaves infiltrated with desired constructs were initially separated into three fractions: supernatant, total microsomal membranes and Golgi-enriched microsomal membranes. The highest GALT activity was observed in Golgi-enriched detergent permeablized microsomal membranes (Additional file 1: Table S4), and thus this fraction was subsequently used as the enzyme source in transient assays (Fig. 1). Here, five of the six GALTs (i.e., GALT2-GALT6) displayed Hyp-O-GALT activity, when compared to controls [tobacco WT leaves alone or infiltrated with either an empty vector or an unrelated glycosyltransferase gene, sialyl transferase (ST)]. Previously characterized GALT2 and GALT5 were used as positive controls for this assay, while GALT1 effectively served as a negative control, given its involvement with $N$-glycan biosynthesis $[15,16,24]$.

\section{Substrate specificities of GALT2-GALT6}

Various potential substrate acceptors were tested to investigate enzyme specificity of GALT3, GALT4, and GALT6. Namely, $[\mathrm{AO}]_{7},[\mathrm{AO}]_{14}$, and $\mathrm{d}[\mathrm{AO}]_{51}$, consisting of non-contiguous peptidyl Hyp residues, were used to examine the effect of these model AGP peptide sequences of various lengths on GALT activity. $[\mathrm{AP}]_{7}$, consisting of alternating Ala and Pro residues, was tested for the requirement of peptidyl Hyp for galactosylation. ExtP, a chemically synthesized extensin peptide consisting of contiguous peptidyl Hyp residues, tested whether contiguous peptidyl Hyp residues act as potential acceptors. Two commercially available pectic polysaccharides, Rhamnogalactan I from potato and Rhamnogalactan (a mixture of RGI and RGII) from soybean, were also tested as potential substrates acceptors. All the non-AGP substrate acceptors, including $[\mathrm{AP}]_{7}$, failed to incorporate

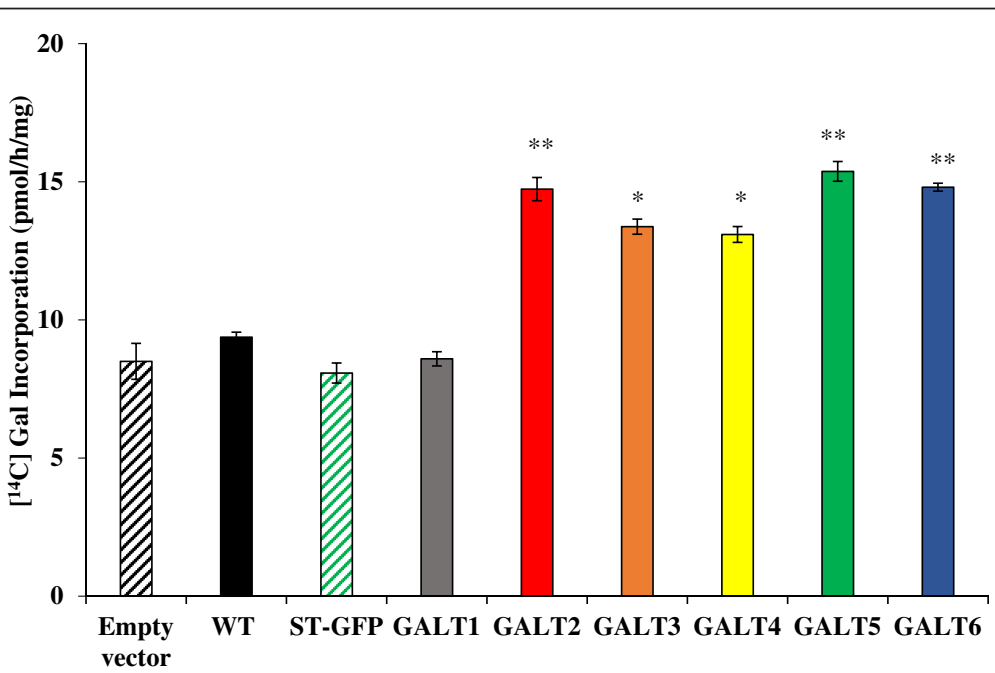

Fig. 1 Hyp-O-GALT activity of GALT1-GALT6 transiently expressed in N. tabacum. GALT1-GALT6 were expressed in epidermal cells of tobacco leaves by Agrobacterium-mediated transient expression, which were used for the preparation of Golgi-enriched microsomal membrane proteins for the Hyp-GALT assays. Synthetic peptide $[A O]_{7}$ was used as substrate acceptor. WT tobacco leaves infiltrated with Agrobacterium GV3101 strain (Empty vector), WT tobacco leaves, and WT tobacco leaves infiltrated with ST fused with GFP were used as controls. Experiments were performed using duplicate samples and data represent the mean \pm SD from two independent experiments. Asterisks indicate mean values significantly different from the WT (Dunnett's test, ${ }^{*} P<0.05$; ${ }^{* *} P<0.01$ ) 
$\left[{ }^{14} \mathrm{C}\right] \mathrm{Gal}$, indicating the GALT activity was specific for AGP sequences containing non-contiguous peptidyl Hyp (Fig. 2). It is interesting to note that GALT2 and GALT5 expressed in tobacco displayed higher activity than when expressed in Pichia, even after taking into account the relatively high background activity in tobacco. This indicates that there are plant-specific factors or accessory proteins critical for Hyp-O-GALT activity $[15,16]$.

\section{Additional biochemical characterization of Hyp-O-GALTs}

Heterologously expressed Hyp-O-GALTs required the divalent cation $\mathrm{Mn}^{+2}$ for maximal activity and utilized UDP- galactose solely as the sugar donor (Additional file 1: Figure S3). This is in contrast to GALT2 and GALT5 expressed in Pichia, which required $\mathrm{Mg}^{+2}$ for its optimal activity $[15,16]$.

\section{Expression profiles of the Hyp-O-GALT genes}

qRT-PCR and data mining of public databases were used to analyze expression profiles of the Hyp-O-GALT genes. qRT-PCR analysis indicated that GALT1-GALT6 are broadly expressed and have overlapping but distinct expression patterns (Fig. 3). These Q-PCR data were in good agreement with public expression data available from GENEVESTIGATOR and the eFP browser [30, 31] as well as from the previous study by Strasser et al. [24] (Additional file 1: Figure S4). Data from large-scale transcriptomic databases were used to provide insight into GALT expression and provide clues as to where to focus phenotypic analysis of GALT knockout mutant plants. Notable patterns of expression were as follows: highest expression of GALT6 was observed in senescent leaves followed by seed, seed coat, root hairs, flowers, and siliques, whereas GALT4 was predominantly expressed in young flowers, mature flowers with siliques and mature siliques. GALT3 was abundant in roots, mature pollen, and hypocotyl (Additional file 1: Figure S4).

Numerous studies indicate that pollen tubes undergo dramatic transformations while growing in the pistil, where they rapidly grow, perceive and respond to navigational cues secreted by the pistil, with AGPs playing a critical role in such interactions [32-34]. Nonetheless, genes expressed by pollen tubes in response to growth in the pistil are poorly characterized. Qin et al. [35] utilized the novel combination of semi in vitro pollination followed by microarray analysis to identify genes specifically involved in pollen-pistil interaction, including the Hyp-O-GALTs. GALT5 had the highest expression followed by GALT2 and GALT4, whereas HPGT3 was only expressed in later stages of pollen elongation. Furthermore, it is interesting to note that there was a temporal difference in the expression patterns of these Hyp-O-GALTs during pollen elongation (Additional file 1: Figure S4).

In addition, transcriptome analyses using RNA extracted from laser-capture dissected seed coat tissue (http://seedgenenetwork.net/arabidopsis) indicated that all five Hyp$O-G A L T$ transcript levels displayed unique expression patterns in the seed coat during embryogenesis (Additional

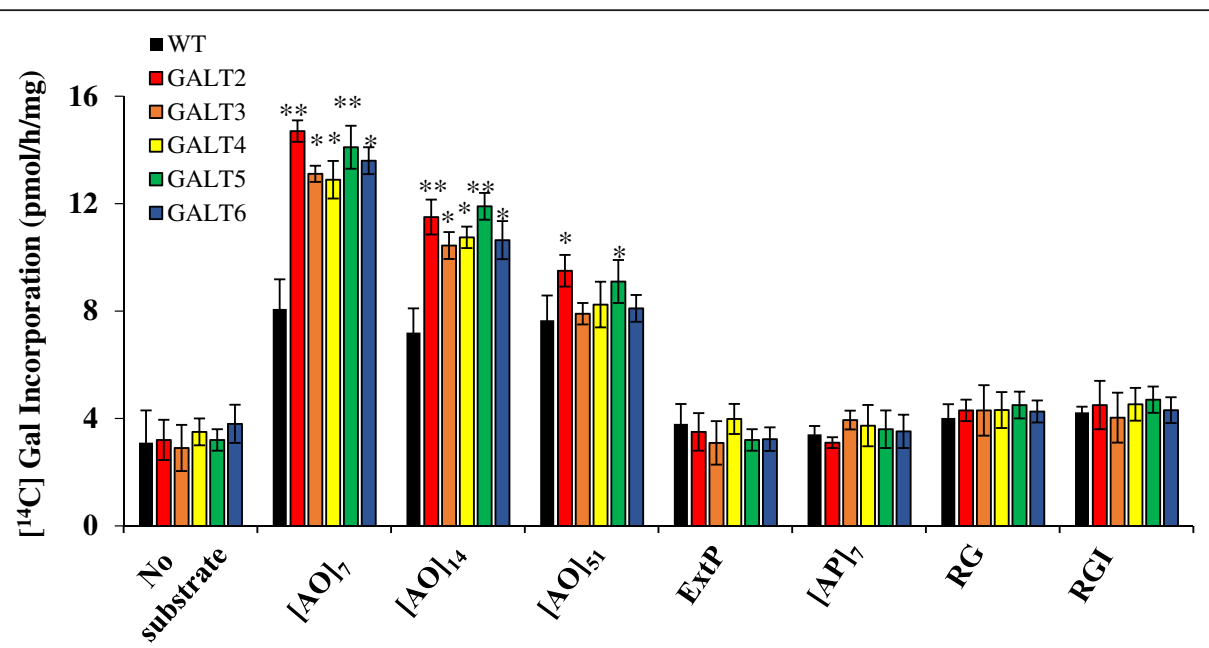

Fig. 2 Substrate specificity of transiently expressed GALT2-6. Detergent permeablized tobacco microsomal membranes obtained from transiently expressed GALT2-6 served as the enzyme source in the GALT reactions. Various peptide and polysaccharide acceptor substrates were tested including: 1) $[\mathrm{AO}]_{7},[\mathrm{AO}]_{14}$, and $\mathrm{d}[\mathrm{AO}]_{51}$ which contain 7,14 , and 51 [AO] units, respectively, 2) a chemically synthesized extensin peptide (ExtP) containing repetitive $\mathrm{SO}_{4}$ units, 3) $[\mathrm{AP}]_{7}$ which contains 7 [AP] units, 4) Rhamnogalactan I (RGI) from potato pectin, and 5) RG from soybean pectin. Microsomes obtained from WT tobacco leaves infiltrated with empty pMDC32 vector were used as a negative control and depicted as WT. Enzyme reactions were done in triplicate and mean values \pm SE are presented. Asterisks indicate values significantly different from the WT (Dunnett's test, ${ }^{*} P<0.05$; ${ }^{*} P<0.01$ ) 


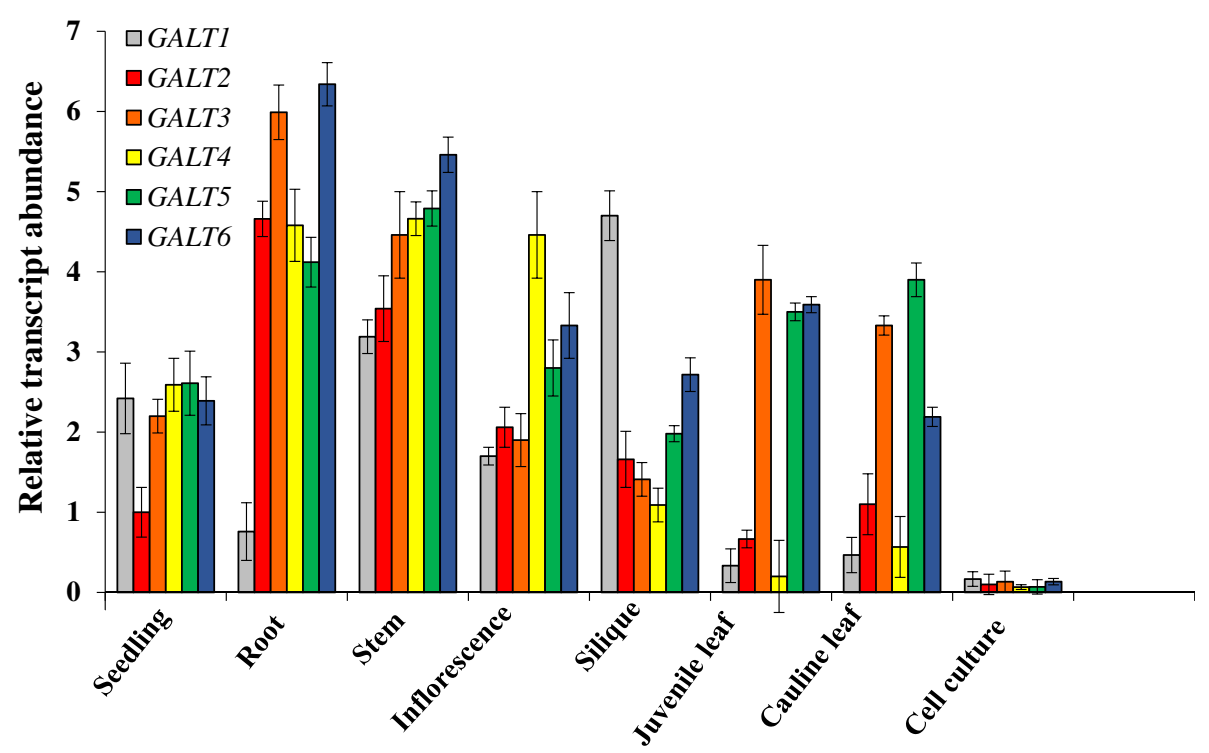

Fig. 3 Expression patterns of the six membered GALT gene family. QPCR analysis of GALT1-GALT6 expression Arabidopsis organs and cell cultures. Roots were obtained from 14 day old seedlings grown on MS plates with $1 \%$ sucrose and a week old cell suspension culture was used for RNA extraction. The level of expression was calculated relative to the UBQ10 gene (mean \pm SE of three biological replicates)

file 1: Figure S5) [36]. Notably, GALT6 was expressed throughout seed development, while expression of GALT2 and GALT5 transcripts was higher in the early stages compared to the later stages of seed development. In contrast, GALT4 was only observed at later stages of seed development, while GALT3 showed the least expression in seeds.

\section{GALT3, GALT4, and GALT6 are targeted to Golgi vesicles}

Transient expression of C-terminal YFP fusions to GALT3, GALT4, and GALT6 were infiltrated in $N$. tobaccum epidermal leaf cells to examine the subcellular localization of these enzymes (Fig. 4). Overlays of GALT3-YFP, GALT4-YFP, and GALT6-YFP individually co-expressed with the Golgi marker protein, sialyl transferase, fused to GFP (ST-GFP) indicated that all three GALTs were localized to the Golgi apparatus. Furthermore, the possibility that they were localized in the ER was excluded, as the GALT-YFP fusion constructions were not co-localized with the ER marker, HDEL fused with GFP (HDEL-GFP). Singly infiltrated controls for ST-GFP, HDEL-GFP, and GALT-YFP were analyzed to optimize gain and pinhole settings for each channel and to exclude any bleed through fluorescence between channels (Additional file 1: Figure S6).

\section{GALT3, GALT4, and GALT6 mutants show AGP biochemical defects}

Two independent allelic mutant lines with T-DNA insertions were identified for each of the six GALT genes in order to examine the biochemical roles of the Hyp-O-
GALTs in vivo. Homozygous mutants were generated, identified by PCR, and confirmed by sequencing (Fig. 5a). RT-PCR and qRT-PCR analysis showed that virtually no transcripts could be detected in the mutants (Fig. 5b and c). Significant reductions in GALT activity as well as $\beta$-Gal-Yariv precipitable AGPs obtained from 14-d old seedlings were observed in knock-out mutants of GALT3 (galt3-1 and galt3-2), GALT4 (galt4-1 and galt4-2), and GALT6 (galt6-1 and galt6-2) compared to WT (Table 1). Such reductions were previously reported for knock-out mutants of GALT2 (galt2-1 and galt2-2), GALT5 (galt5-1 and galt5-2), and a galt2galt5 double mutant and were used here as positive controls [16]. Consistent with the findings that GALT1 synthesizes Lewis a structures and lacks Hyp-O-GALT activity (Fig. 1), knockout mutants of GALT1 (galt1-1 and galt1-2) demonstrated no such reductions and were indistinguishable from WT (Table 1) [24].

Given the differential expression of these Hyp-OGALTs and the broad expression of AGPs, AGPs were also quantified from other organs in the mutants. Similar patterns of reductions in $\beta$-Gal-Yariv precipitable AGPs were observed in these other organs for these mutants. In general, disruption of any of the five GALTS (GALT2GALT6) caused a significant reduction in AGP content, with most significant effects being exhibited by galt 5 in stems, galt4 in siliques, and galt6 in senescent leaves (Table 2). These data on AGP quantification in the mutants were consistent with the expression profile data for GALT2-GALT6. Profiles of these $\beta$-Gal-Yariv precipitable 
GALT3-YFP and HDEL-GFP co-infiltration

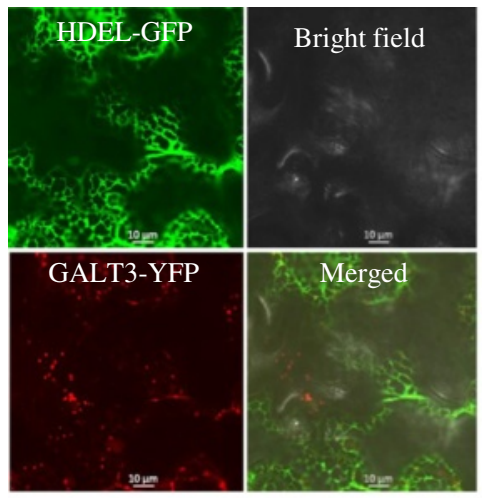

GALT4-YFP and HDEL-GFP co-infiltration

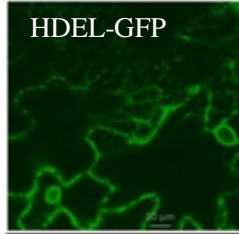

GALT4-YFP

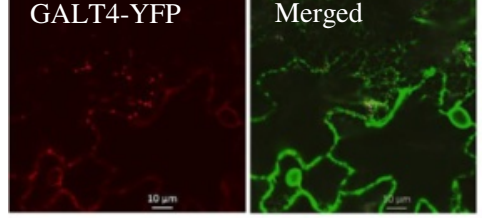

GALT6-YFP and HDEL-GFP co-infiltration

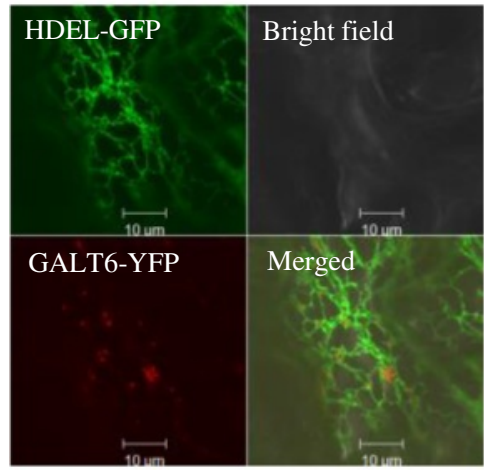

GALT3-YFP and ST-GFP co-infiltration

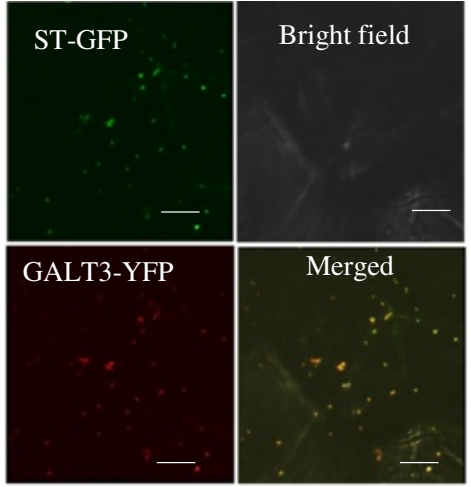

GALT4-YFP and ST-GFP co-infiltration

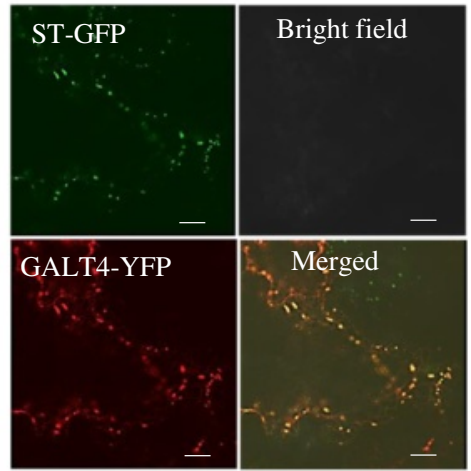

GALT6-YFP and ST-GFP co-infiltration
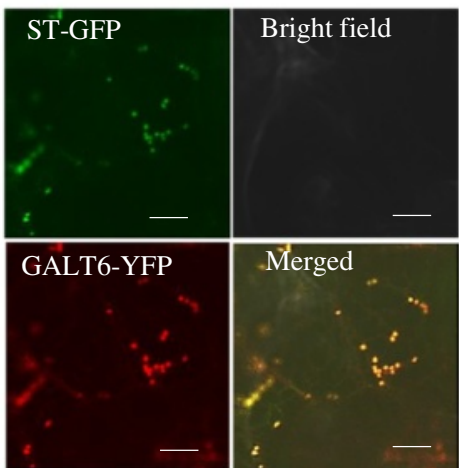

Fig. 4 Subcellular localization of transiently expressed GALT3-YFP, GALT4-YFP, and GALT6-YFP in N. tabacum. GALT3-YFP, GALT4-YFP, and GALT6-YFP fusion constructions were expressed under the control of the CaMV $35 S$ promoter in N. tabacum. Transiently expressed GALT3-YFP, GALT4-YFP, and GALT6-YFP co-localized with sialyl transferase (ST)-GFP fusion protein (a Golgi marker), but not with HDEL-GFP fusion protein (an ER marker). These constructs were examined by laser-scanning confocal microscopy under fluorescent and white light, and the fluorescent images were merged to observe co-localization. Size bar $=10 \mu \mathrm{m}$

AGPs produced by RP-HPLC were also examined for various galt mutants and revealed that virtually all these AGPs, as opposed to a single or subset of these AGPs, were affected when compared to WT or galt1 control profiles (Additional file 1: Figure S7). Furthermore, the AGP peaks in the galt3, galt4, and galt6 mutants eluted later and thus had less glycosylated protein compared to the WT or galt1 control AGP peaks, consistent with reduced Hyp-galactosylation.

\section{GALT3, GALT4, and GALT6 mutants exhibit root hair} defects

To investigate the physiological function of these six GALTs in vivo, mutants were grown on MS plates and compared to WT. No significant phenotypic differences in primary root growth were observed with the exception of the root hairs. Single mutant knock-out lines for GALT3, as well as for GALT2 and GALT5 and the galt2galt5 double mutant, consistently displayed shorter and 


\section{A $\quad$ GALT1}

GALT3
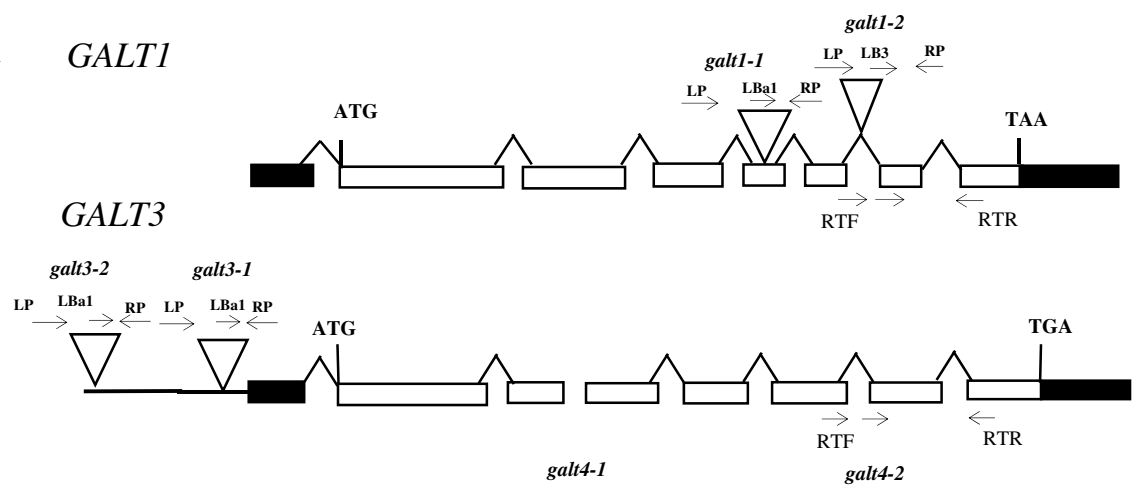

GALT4

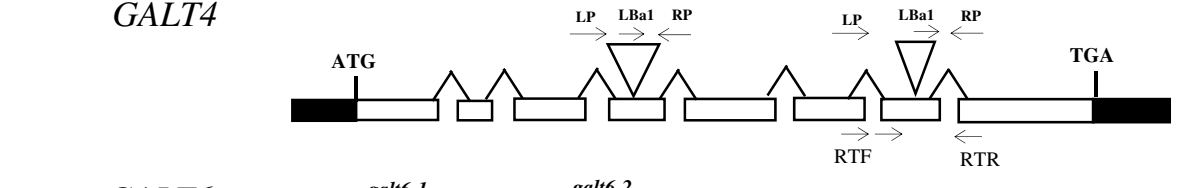

$\stackrel{\text { LP }}{\longrightarrow} \stackrel{\text { LBa1 }}{\rightarrow} \stackrel{\text { RP }}{\leftarrow}$

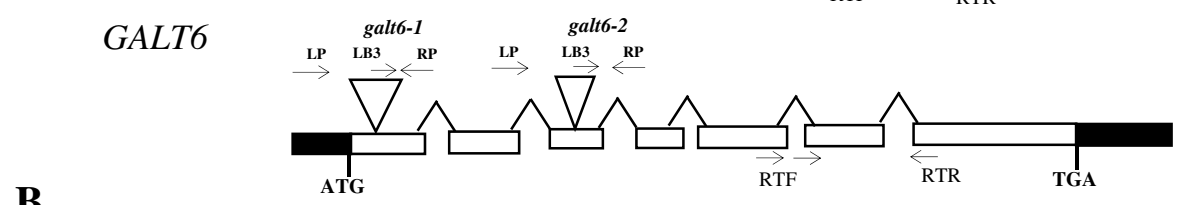

B
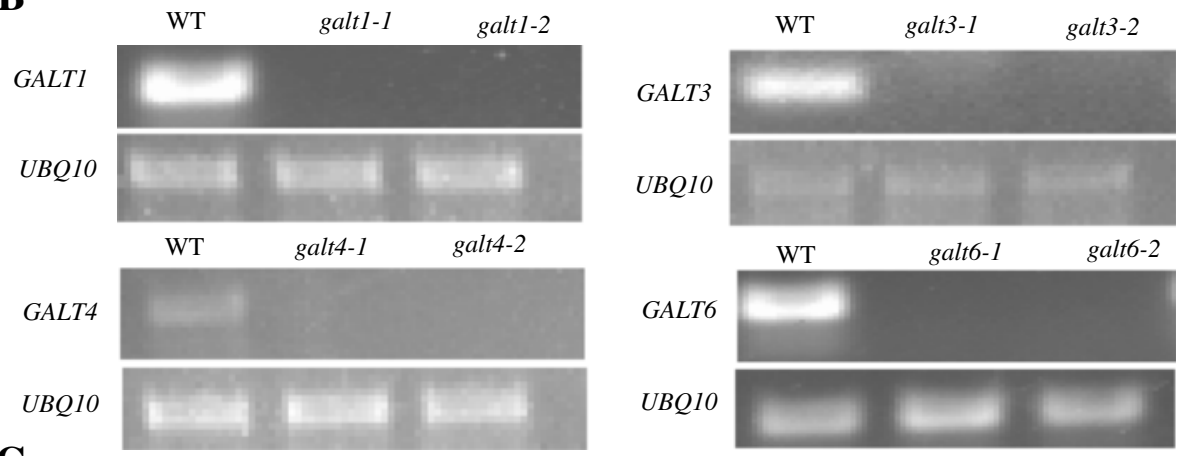

C

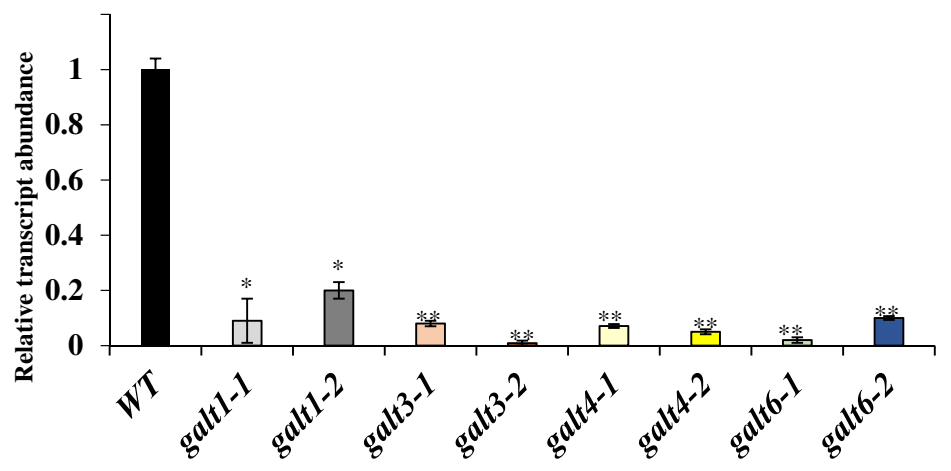

Fig. 5 Schematic gene models, locations of T-DNA mutant insertions, and transcript analysis of GALT1, GALT3, GALT4, and GALT6. a GALT1, GALT3. GALT4 and GALT6 gene structures and T-DNA insertion sites in galt1-1, galt1-2, galt3-1, galt3-2, galt4-1, galt4-2, galt6-1, and galt6-2 mutants. The intron-exon structures of GALT1, GALT3, GALT4, and GALT6 are indicated (introns are drawn as lines and exons as rectangles, with white rectangles representing coding sequences and black rectangles representing UTRs). Sites of T-DNA insertions are marked (triangles) as are the locations of primer sequences (arrows above the genes) used for PCR screening. b RT-PCR analysis of transcripts from rosette leaves of 14-day-old WT (Col-0) and allelic homozygous galt1, galt3, galt4 and galt6 mutant lines. Arrows below the genes in (a) indicate the position of primers (denoted as RTF and RTR) used for RT-PCR analysis of transcript levels. UBQ10 primers were used as internal controls. c Quantitative real-time reverse transcription -PCR (qRT-PCR) analysis was performed to quantify and compare transcript levels of the indicated genes with that of corresponding WT gene. In other words, the relative expression level of the GALT genes in the mutants was compared to WT values, which were set to a value of 1.0 for each of the GALT genes. Asterisks indicate values significantly different from the WT expression of the indicated genes (Dunnett's test, ${ }^{*} P<0.01$; ${ }^{*} P<0.001$ ) 
Table 1 GALT activity and amount of $\beta$-Gal-Yariv precipitated AGPs in WT and galt mutants

\begin{tabular}{llc}
\hline Genotype & $\begin{array}{l}\text { GALT activity } \\
(\mathrm{pmol} / \mathrm{h} / \mathrm{mg})\end{array}$ & $\begin{array}{l}\text { B-Gal-Yariv precipitated } \\
\text { AGPs }(\mu \mathrm{g} / \mathrm{g})\end{array}$ \\
\hline WT & $7.10 \pm 0.90$ & $13.60 \pm 0.75$ \\
galt1-1 & $6.80 \pm 0.37$ & $13.30 \pm 0.95$ \\
galt1-2 & $7.20 \pm 0.65$ & $13.30 \pm 0.95$ \\
galt2-1 & $5.53 \pm 1.20^{\mathrm{b}}$ & $9.91 \pm 2.80^{\mathrm{b}}$ \\
galt2-2 & $5.90 \pm 1.01^{\mathrm{b}}$ & $9.28 \pm 1.50^{\mathrm{b}}$ \\
galt3-1 & $6.08 \pm 1.20^{\mathrm{a}}$ & $12.10 \pm 0.95$ \\
galt3-2 & $5.51 \pm 1.01^{\mathrm{b}}$ & $12.30 \pm 0.80^{\mathrm{a}}$ \\
galt4-1 & $6.04 \pm 2.20^{\mathrm{a}}$ & $12.00 \pm 1.10^{\mathrm{a}}$ \\
galt4-2 & $5.83 \pm 1.50^{\mathrm{b}}$ & $11.90 \pm 1.20^{\mathrm{a}}$ \\
galt5-1 & $5.45 \pm 1.10^{\mathrm{b}}$ & $7.90 \pm 2.10^{\mathrm{b}}$ \\
galt5-2 & $4.90 \pm 1.50^{\mathrm{b}}$ & $8.10 \pm 1.20^{\mathrm{b}}$ \\
galt6-1 & $5.30 \pm 0.44^{\mathrm{b}}$ & $10.90 \pm 0.59^{\mathrm{a}}$ \\
galt6-2 & $5.00 \pm 1.71^{\mathrm{b}}$ & $10.30 \pm 1.54^{\mathrm{a}}$ \\
galt2galt5 & $4.64 \pm 0.54^{\mathrm{b}}$ & $5.63 \pm 0.39^{\mathrm{b}}$ \\
\hline
\end{tabular}

Detergent-solubilized microsomal fractions were used for performing a standard Hyp-GALT assay, and AGPs were extracted, precipitated by $\beta$-GalYariv reagent, and quantified from 14-day-old plants. The values are averages of at least two independent experiments from two biological replicates. Letters ' $a$ ' and ' $b$ ' denote a significant difference from the wild type (Dunnett's test, $P<0.05 ; P<0.01$ ) respectively

less dense root hairs compared to WT; knock-out lines for GALT6, GALT4, and GALT1 displayed either less severe or no such root hair phenotypes (Fig. 6).

\section{GALT4 and GALT6 mutants display reduced seed set}

The galt4 and galt6 mutants displayed a 16 and $13 \%$ reduction in seed set, respectively (Fig. 7 and Table 3). Reciprocal crosses of the galt4 and galt6 mutants to wild type plants were performed to determine whether this defect was conferred by the male or female gametophyte. Such crosses indicated that the male gametophyte of these mutants was mainly responsible for conferring reduced seed set (Fig. 7 and Table 3). Pollen were consequently examined with Alexander's stain which indicated that pollen were viable (Additional file 1: Figure S8A). Furthermore, in vitro pollen germination did not exhibit altered germination frequency in galt4 and galt6 mutants compared to WT (Additional file 1: Figure S8B and $\mathrm{S} 8 \mathrm{C})$.

\section{GALT3 and GALT6 mutants demonstrate reduced staining of adherent seed coat mucilage}

Prior evidence for the involvement of AGPs (SOS5) and GALT2/GALT5 in seed coat mucilage prompted an examination of the potential functions of GALT3, GALT4, and GALT6 in modifying seed coat mucilage $[16,37,38]$. The effect of disruption of the six GALT gene family members on adherent seed mucilage was
Table 2 Amount of $\beta$-Gal-Yariv precipitated AGPs in WT and galt mutants

\begin{tabular}{llllc}
\hline Genotype & Stem & Silique & Flower & Senescent leaves \\
\hline WT & $35.7 \pm 3.4$ & $15.5 \pm 2.5$ & $17.0 \pm 0.4$ & $28.4 \pm 3.6$ \\
galt1-1 & $34.9 \pm 2.1$ & $15.2 \pm 1.8$ & $16.5 \pm 0.5$ & $28.5 \pm 2.4$ \\
galt1-2 & $35.1 \pm 2.0$ & $15.8 \pm 2.3$ & $17.2 \pm 0.9$ & $28.1 \pm 3.5$ \\
galt2-1 & $25.3 \pm 3.3^{\mathrm{a}}$ & $11.8 \pm 1.3^{\mathrm{a}}$ & $13.9 \pm 0.5^{\mathrm{b}}$ & $24.4 \pm 3.1^{\mathrm{a}}$ \\
galt2-2 & $26.1 \pm 2.7^{\mathrm{a}}$ & $11.5 \pm 1.7^{\mathrm{a}}$ & $13.4 \pm 0.4^{\mathrm{b}}$ & $24.0 \pm 2.6^{\mathrm{a}}$ \\
galt3-1 & $29.2 \pm 4.1$ & $12.5 \pm 0.6^{\mathrm{a}}$ & $15.7 \pm 0.7^{\mathrm{a}}$ & $26.9 \pm 3.8^{\mathrm{a}}$ \\
galt3-2 & $28.6 \pm 2.9$ & $11.9 \pm 1.2^{\mathrm{a}}$ & $15.0 \pm 0.2^{\mathrm{a}}$ & $27.0 \pm 2.2$ \\
galt4-1 & $29.7 \pm 3.7$ & $9.9 \pm 0.8^{\mathrm{b}}$ & $11.9 \pm 0.1^{\mathrm{b}}$ & $27.1 \pm 2.4$ \\
galt4-2 & $29.5 \pm 1.5$ & $8.3 \pm 0.5^{\mathrm{b}}$ & $12.1 \pm 0.4^{\mathrm{b}}$ & $27.5 \pm 3.1$ \\
galt5-1 & $23.6 \pm 3.3^{\mathrm{b}}$ & $10.7 \pm 0.9^{\mathrm{b}}$ & $12.7 \pm 0.9^{\mathrm{b}}$ & $25.1 \pm 3.5^{\mathrm{a}}$ \\
galt5-2 & $23.7 \pm 2.8^{\mathrm{b}}$ & $11.1 \pm 0.4^{\mathrm{a}}$ & $12.9 \pm 0.8^{\mathrm{b}}$ & $24.9 \pm 4.6^{\mathrm{a}}$ \\
galt6-1 & $27.3 \pm 2.3^{\mathrm{a}}$ & $10.4 \pm 0.7^{\mathrm{b}}$ & $12.2 \pm 0.4^{\mathrm{b}}$ & $23.0 \pm 3.7^{\mathrm{b}}$ \\
galt6-2 & $26.9 \pm 3.6^{\mathrm{a}}$ & $11.2 \pm 0.8^{\mathrm{a}}$ & $12.4 \pm 0.7^{\mathrm{b}}$ & $22.0 \pm 2.9^{\mathrm{b}}$ \\
galt2galt5 & $25.3 \pm 2.4^{\mathrm{a}}$ & $11.0 \pm 0.9^{\mathrm{a}}$ & $12.3 \pm 0.5^{\mathrm{b}}$ & $24.5 \pm 3.1^{\mathrm{a}}$ \\
\hline
\end{tabular}

Letters ' $a$ ' and ' $b$ ' denote a significant difference from the wild type (Dunnett's test, $P<0.05 ; P<0.01$; respectively). Stem, silique, and flowers were obtained from 30-day-old plants, whereas senescent leaves were obtained from 45-day-old plants

investigated by staining hydrated seeds with ruthenium red, which stains negatively charged biopolymers such as pectin [39]. The galt3-1, galt3-2, galt6-1, galt6-2, and galt2galt 5 mutant seeds showed a thin staining pattern of the adherent mucilage, whereas WT, galt2, galt4, galt5, and galt1 seeds showed an intense, regular, spherical staining pattern (Fig. 8). In addition, adherent mucilage mass and volume were measured to confirm the reduction of adherent mucilage thickness. No difference was observed in adherent mucilage mass between WT and galt single and double mutant seeds, whereas the adherent mucilage size of galt3, galt6, and galt2galt5 was substantially reduced $(20 \sim 30 \%)$ compared with WT (Table 4). In contrast, galt1, galt4, galt2, and galt5 mutants were less dramatically altered $(5 \sim 13 \%)$ compared to WT.

In order to confirm and quantify the changes in nonadherent (soluble) and adherent mucilage, WT and galt mutant seeds were analyzed. Sequential extraction of seeds with ammonium oxalate, $0.2 \mathrm{~N} \mathrm{NaOH}$, and $2 \mathrm{~N}$ $\mathrm{NaOH}$ was performed to assess changes in the soluble and adherent mucilage (Table 5). Both galt6 and galt3 seeds had a significant increase in the total sugar present in the ammonium oxalate and $0.2 \mathrm{~N} \mathrm{NaOH}$ extracts (soluble and weakly attached pectins) compared to wild type seeds (or galt1 mutants). Less significant differences were observed in galt2, galt4, and galt5 single mutants, whereas more significant differences were observed in galt2galt5 mutants. All the galt mutants except for galt1 displayed a decrease in total sugars in the $2 \mathrm{~N} \mathrm{NaOH}$ extracts, which represent the majority of the adherent 


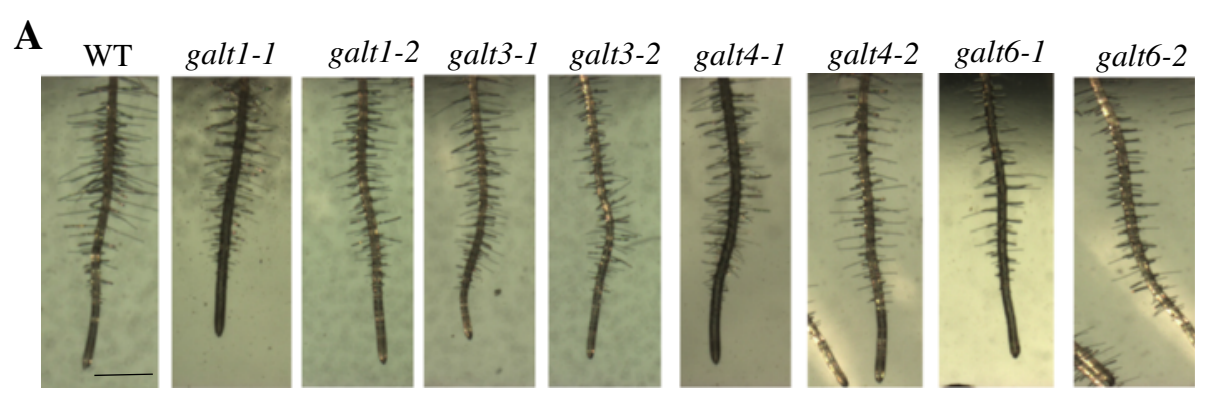

B
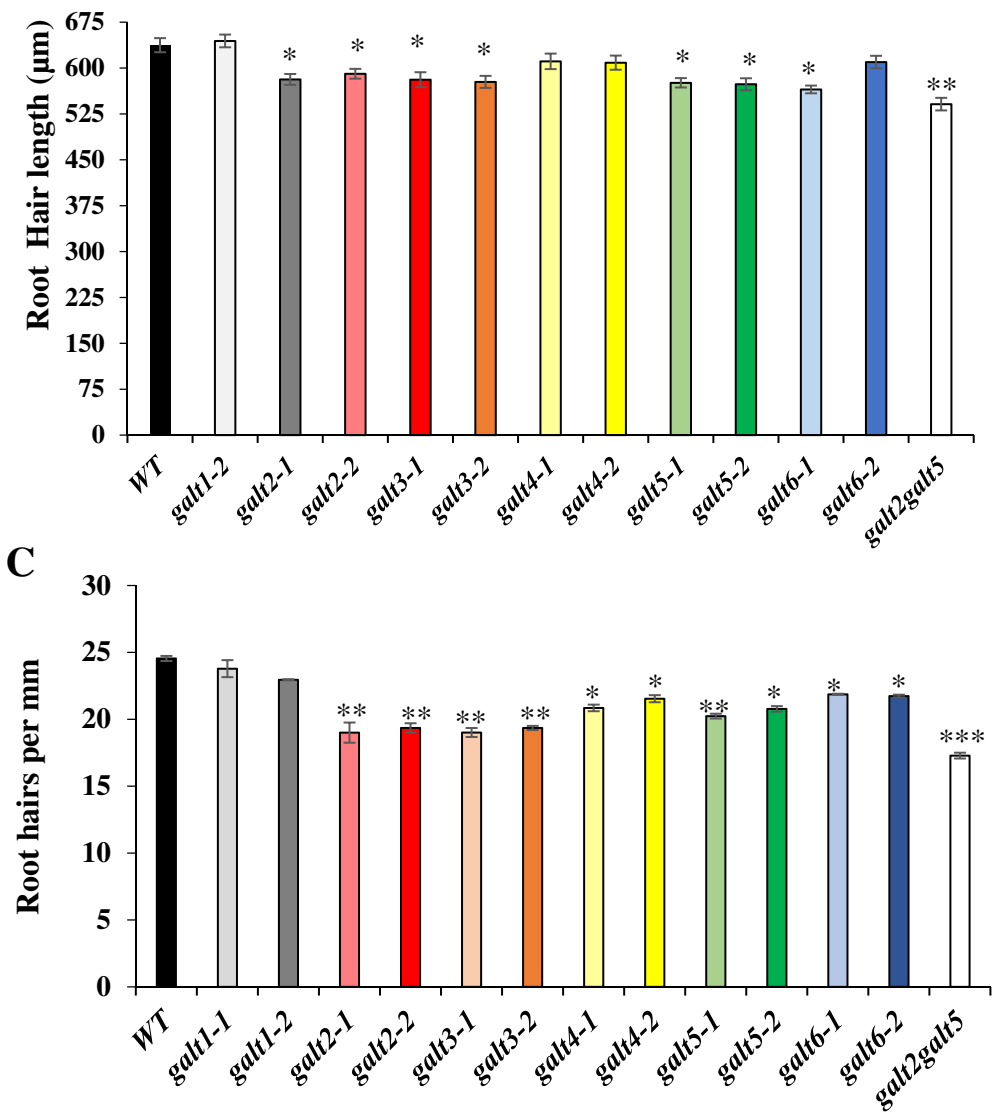

Fig. 6 Root hair length and density reduced in the galt3, galt4, and galt6 mutants. a WT, galt1, galt3, galt4, and galt6 plants were grown on MS agar plates for 10 days. Bar $=1 \mathrm{~mm}$. $\mathbf{b}$ Quantification of root hair length and $\mathbf{c}$ root hair density of the galt mutants. Asterisks indicate significantly reduced root hair length and density compared with WT controls according to Dunnett's test $\left({ }^{*} P<0.05 ;{ }^{*} P<0.01 ; n>300\right)$

mucilage and contain strongly linked pectins and crosslinking glycans/hemicelluloses [40, 41].

\section{GALT6 mutants demonstrate premature senescence}

Only the GALT6 mutants (galt6-1 and galt6-2) displayed early onset of senescence compared to WT and the other galt mutants. This was visualized by premature yellowing of leaves and was correlated with a slightly greater reduction in chlorophyll content and protein content in GALT6 mutants compared to WT (Additional file 1: Figure S9). These observations were consistent with the abundance of GALT6 transcripts in senescent leaves as well as with the markedly greater reduction of $\beta$-GalYariv precipitable AGPs in galt6 senescent leaves (Additional file 1: Figure S4; Table 2).

\section{GALT3, GALT4, and GALT6 mutants exhibit pollen tube} and root growth which is less sensitive to $\beta$-Gal-Yariv reagent

The galt3, galt4, and galt6 mutants displayed reduced inhibition of pollen tube and root growth elongation in response to $\beta$-Gal-Yariv reagent compared to WT or $\alpha$-GalYariv reagent control treatments (Figs. 9, 10, Additional file 1: Figure S10). As expected, GALT1 mutants did not 


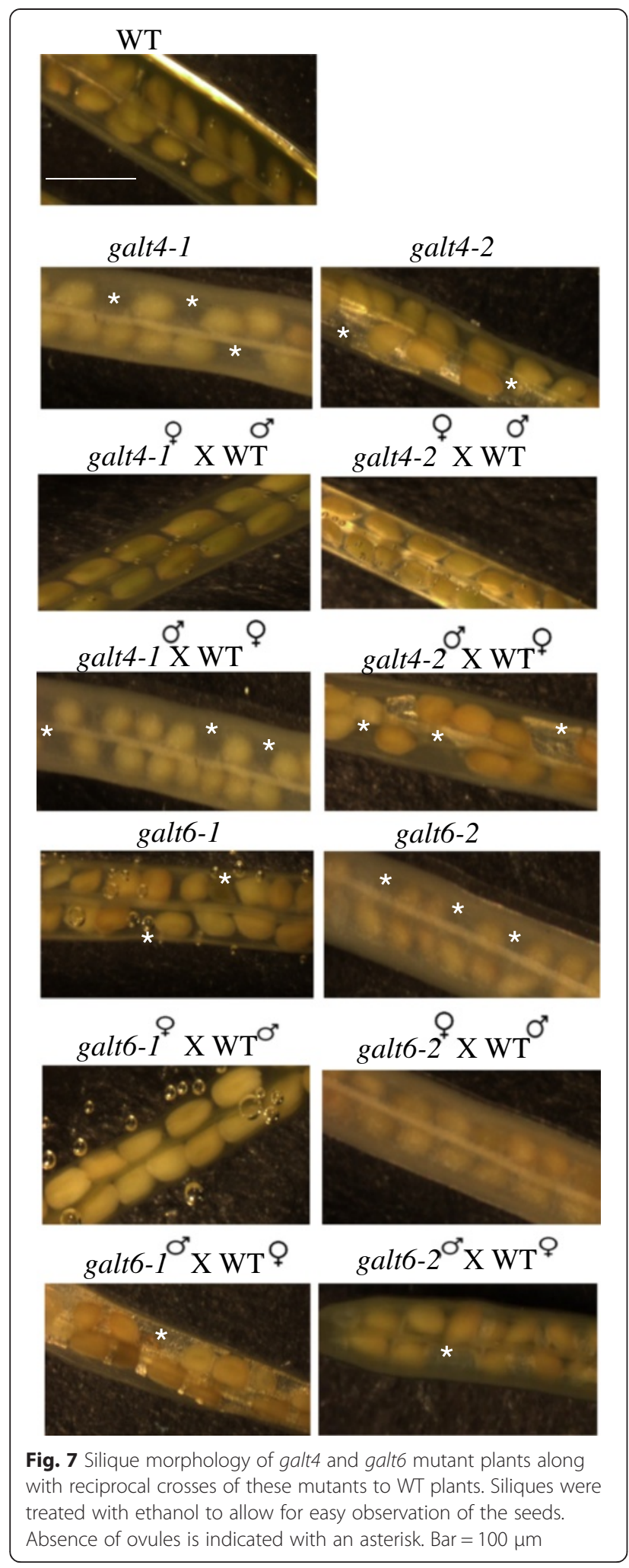

exhibit any difference in either pollen tube or root growth elongation compared to WT. Moreover, no significant difference in pollen tube or primary root growth elongation
Table 3 Weight, length, and seed number from WT and galt siliques

\begin{tabular}{|c|c|c|c|}
\hline Genotype & Silique length (mm) & Seeds/Silique & $\begin{array}{l}\text { Seed weight } \\
\text { (mg) }\end{array}$ \\
\hline WT $q \times$ WT $\hat{O}$ & 12.90 & $56.10 \pm 3.80$ & $4.50 \pm 0.34$ \\
\hline galt1-20 $\times$ galt1-20 & $13.04 \pm 0.84$ & $54.87 \pm 2.70$ & $4.65 \pm 0.28$ \\
\hline galt2-1우 × galt2-10 & $12.51 \pm 0.22$ & $52.45 \pm 3.52$ & $4.20 \pm 0.91$ \\
\hline galt2-20 $\times$ galt $2-2 \hat{0}$ & $13.21 \pm 0.34$ & $53.65 \pm 2.93$ & $4.65 \pm 0.44$ \\
\hline galt3-1우 $\times$ galt3-10 & $13.06 \pm 0.68$ & $52.12 \pm 3.29$ & $4.63 \pm 0.34$ \\
\hline galt3-2q $\times$ galt3-20 & $12.80 \pm 0.77$ & $53.37 \pm 2.66$ & $4.50 \pm 0.37$ \\
\hline alt4-1 $q \times$ galt $4-1 \widehat{0}$ & 13.06 & $47.37 \pm 2.28^{b}$ & $3.26 \pm 0.40^{\mathrm{a}}$ \\
\hline galt4-2Q $\times$ galt4-2犬 & $12.85 \pm 0.59$ & $47.50 \pm 2.44^{b}$ & $3.41 \pm 0.32^{\mathrm{a}}$ \\
\hline galt5-1우 $\times$ galt5-1 $\widehat{\delta}$ & $13.32 \pm 0.34$ & $53.67 \pm 3.4$ & $4.23 \pm 0.54$ \\
\hline galt5-2q $\times$ galt5-20 & $13.65 \pm 0.89$ & $55.28 \pm 2.7$ & $4.67 \pm 0.89$ \\
\hline galt6-1 $9 \times$ galt6-10 & $13.10 \pm 0.57$ & $49.11 \pm 4.24^{b}$ & $3.41 \pm 0.18^{a}$ \\
\hline galt6-2q $\times$ galt6-20 & $13.60 \pm 0.56$ & $50.56 \pm 2.79^{b}$ & $3.72 \pm 0.27^{\mathrm{a}}$ \\
\hline WTO+ $\times$ galt4-1 ô $^{-1}$ & $13.10 \pm 0.73$ & $45.10 \pm 6.40^{b}$ & $3.70 \pm 0.56^{\mathrm{a}}$ \\
\hline 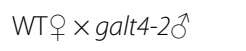 & $12.91 \pm 0.45$ & $43.45 \pm 4.90^{\mathrm{b}}$ & $3.54 \pm 0.38^{\mathrm{a}}$ \\
\hline galt4-1우 $\times$ WTổ & $13.06 \pm 0.56$ & $53.37 \pm 4.28$ & $4.56 \pm 0.40$ \\
\hline galt4-2Q $\times$ WTô & 12.85 & $52.10 \pm 1.40$ & $4.34 \pm 0.62$ \\
\hline WT우 $\times$ galt6-1 $\hat{\sigma}$ & $13.00 \pm 0.54$ & $49.70 \pm 7.40^{b}$ & $3.50 \pm 0.56^{\mathrm{a}}$ \\
\hline WTo $\times$ galt6-2 0 & 0.47 & $50.60 \pm 4.40^{\mathrm{b}}$ & $3.50 \pm 0.56^{\mathrm{a}}$ \\
\hline galt6-1우 $\times$ WTổ & $13.06 \pm 0.71$ & $53.37 \pm 4.28$ & $4.56 \pm 0.40$ \\
\hline galt6-2o $\times$ WTô & $13.13 \pm 0.96$ & $53.37 \pm 4.28$ & $4.56 \pm 0.40$ \\
\hline
\end{tabular}

Siliques were obtained from 6-week-old plants $(n=20)$. Letters ' $a$ ' and ' $b$ ' denote a significant difference from the wild type (Dunnett's test, $P<0.05$; $P<0.01$ respectively)

was observed in unsupplemented germination media, indicating the conditional nature of this phenotype (Figs. 9 and 10).

\section{Conditional salt hypersensitive phenotypes of the galt mutants}

GALT3 (galt3-1 and galt3-2) and GALT6 (galt6-1 and galt6-2) mutants, and to a lesser extent the GALT4 (galt4-1 and galt4-2) mutants, exhibited significant reductions in root elongation compared to WT when grown in the presence of 100 and $150 \mathrm{mM} \mathrm{NaCl}$ (Fig. 11 and Additional file 1: Figure S11). Such reductions in root elongation were previously reported for knock-out mutants of GALT2 (galt2-1 and galt2-2), GALT5 (galt5-1 and galt5-2), and the galt2galt5 double mutant [16]. As expected, GALT1 mutants did not show salt hypersensitive growth and were indistinguishable from WT in this assay. The galt single and double mutants were not sensitive to osmotic stress as illustrated by mannitol (Additional file 1: Figure S12).

Microscopic examination of the GALT3, GALT6, and to a lesser extent the GALT4 mutants also revealed defective anisotropic root tip growth (i.e., root tip swelling) 


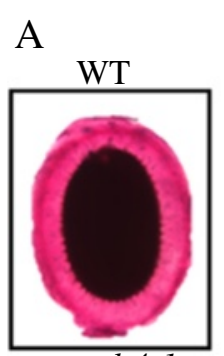

galt4-1

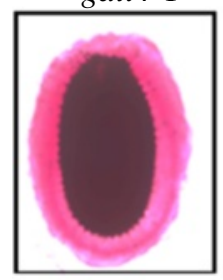

galt2-1

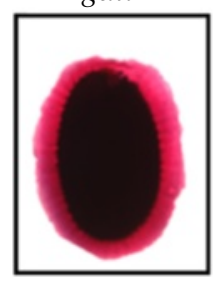

galt1-2

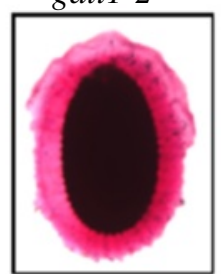

galt4-2

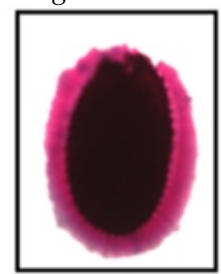

galt5-1

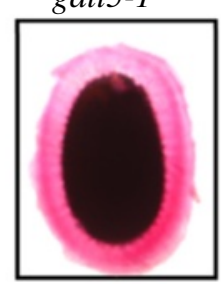

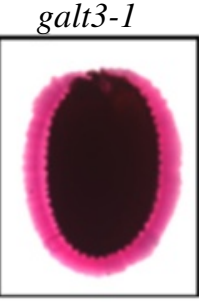

galt6-1

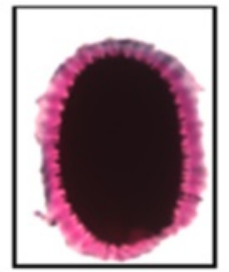

galt 2 galt 5

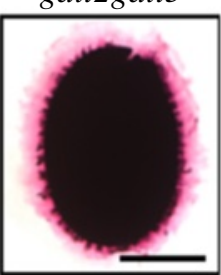

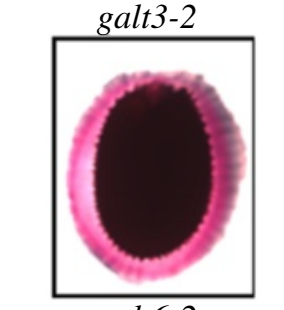

galt6-2

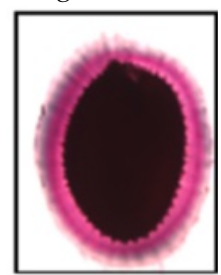

(1)

Fig. 8 Pectin staining of seed coat mucilage in wild type, galt1-galt6 single mutants, and galt2galt5 double mutants. Seeds of the indicated genotypes were prehydrated with water for 90 min and stained with ruthenium red to visualize pectin using a Nikon Phot-lab2 microscope coupled with a SPOT RT color CCD camera and SPOT 4.2 analysis software. Bar $=100 \mu \mathrm{m}$

Table 4 Determination of adherent mucilage mass and size in WT and galt mutants

\begin{tabular}{lll}
\hline Genotype & Mass $(\mu \mathrm{g})$ & Size $\left(\mathrm{mm}^{3}\right)$ \\
\hline WT & $1.82 \pm 0.05$ & $0.47 \pm 0.13$ \\
galt1-2 & $1.76 \pm 0.06$ & $0.45 \pm 0.03$ \\
galt2-1 & $1.80 \pm 0.09$ & $0.44 \pm 0.04^{\mathrm{a}}$ \\
galt2-2 & $1.77 \pm 0.06$ & $0.45 \pm 0.07^{\mathrm{a}}$ \\
galt3-1 & $1.80 \pm 0.09$ & $0.37 \pm 0.08^{\mathrm{b}}$ \\
galt3-2 & $1.75 \pm 0.08$ & $0.35 \pm 0.05^{\mathrm{b}}$ \\
galt4-1 & $1.79 \pm 0.05$ & $0.42 \pm 0.10^{\mathrm{a}}$ \\
galt4-2 & $1.81 \pm 0.05$ & $0.39 \pm 0.20^{\mathrm{a}}$ \\
galt5-1 & $1.80 \pm 0.05$ & $0.41 \pm 0.30^{\mathrm{a}}$ \\
galt5-2 & $1.81 \pm 0.05$ & $0.39 \pm 0.25^{\mathrm{b}}$ \\
galt6-1 & $1.83 \pm 0.04$ & $0.35 \pm 0.04^{\mathrm{b}}$ \\
galt6-2 & $1.77 \pm 0.07$ & $0.37 \pm 0.05^{\mathrm{b}}$ \\
galt2galt5 & $1.75 \pm 0.09$ & $0.30 \pm 0.05^{\mathrm{b}}$ \\
\hline
\end{tabular}

The mass and size values are the average mass and size of adherent mucilage of 100 seeds of triplicate assays \pm SE. Letters ' $a$ ' and ' $b$ ' denote a significantly difference from the wild type (Dunnett's test, $P<0.05 ; P<0.01$ respectively) in the presence of $100 \mathrm{mM} \mathrm{NaCl}$, which was not observed in WT and GALT1 mutants (Additional file 1: Figure S13). Such salt hypersensitive root tip swelling responses were previously reported in galt2, galt5, and galt2galt5 mutants and were included here as positive controls [16].

A root bending assay was used as another means to evaluate salt hypersensitivity of the GALT mutants (Additional file 1: Figure S14). This assay is commonly used by plant researchers to evaluate salt sensitivity/tolerance and involves monitoring root growth reorientation after a 180 degree reorientation of the seedling to gravity. Results of this experiment indicated that GALT3 (galt3-1 and galt3-2) and GALT6 (galt6-1 and galt6-2) mutants, and to a lesser extent the GALT4 (galt4-1 and galt4-2) mutants were slow to reorient their root growth compared to WT when grown in the presence of $100 \mathrm{mM} \mathrm{NaCl}$. Such delayed reorientation was previously reported for knock-out mutants of GALT2 (galt2-1 and galt2-2), GALT5 (galt5-1 and galt5-2), and the galt2galt5 double mutant; these mutants were used here as positive controls [16]. As expected, GALT1 mutants (galt1-1 and galt1-2) reoriented quickly and were indistinguishable from WT in this assay. 
Table 5 Quantification of total sugars from WT and galt mucilage sequentially extracted using ammonium oxalate, $0.2 \mathrm{~N} \mathrm{NaOH}$, and $2 \mathrm{~N} \mathrm{NaOH}$

\begin{tabular}{lcll}
\hline & \multicolumn{3}{l}{ Extract $^{\mathrm{a}}$} \\
\cline { 2 - 4 } Genotype & Ammonium oxalate & $0.2 \mathrm{~N} \mathrm{NaOH}$ & $2 \mathrm{~N} \mathrm{NaOH}$ \\
\hline WT & $0.85 \pm 0.05$ & $1.04 \pm 0.03$ & $0.81 \pm 0.04$ \\
galt1-2 & $0.83 \pm 0.07$ & $1.05 \pm 0.05$ & $0.84 \pm 0.03$ \\
galt2-1 & $0.95 \pm 0.03^{\mathrm{b}}$ & $1.12 \pm 0.04^{\mathrm{b}}$ & $0.61 \pm 0.05^{\mathrm{b}}$ \\
galt2-2 & $0.97 \pm 0.70^{\mathrm{b}}$ & $1.19 \pm 0.03^{\mathrm{b}}$ & $0.54 \pm 0.06^{\mathrm{b}}$ \\
galt3-1 & $1.30 \pm 0.09^{\mathrm{c}}$ & $1.29 \pm 0.05^{\mathrm{c}}$ & $0.53 \pm 0.05^{\mathrm{b}}$ \\
galt3-2 & $1.28 \pm 0.05^{\mathrm{c}}$ & $1.27 \pm 0.07^{\mathrm{c}}$ & $0.52 \pm 0.07^{\mathrm{b}}$ \\
galt4-1 & $0.88 \pm 0.20$ & $1.09 \pm 0.02$ & $0.79 \pm 0.01$ \\
galt4-2 & $0.90 \pm 0.60^{\mathrm{b}}$ & $1.01 \pm 0.06$ & $0.73 \pm 0.03$ \\
galt5-1 & $0.95 \pm 0.10^{\mathrm{b}}$ & $1.17 \pm 0.05^{\mathrm{b}}$ & $0.63 \pm 0.05^{\mathrm{b}}$ \\
galt5-2 & $0.90 \pm 0.08^{\mathrm{b}}$ & $1.20 \pm 0.07^{\mathrm{c}}$ & $0.60 \pm 0.04^{\mathrm{b}}$ \\
galt6-1 & $1.25 \pm 0.09^{\mathrm{c}}$ & $1.30 \pm 0.07^{\mathrm{c}}$ & $0.55 \pm 0.05^{\mathrm{b}}$ \\
galt6-2 $_{\text {galt2galt5 }}$ & $1.31 \pm 0.05^{\mathrm{c}}$ & $1.29 \pm 0.04^{\mathrm{c}}$ & $0.61 \pm 0.08^{\mathrm{b}}$ \\
\hline
\end{tabular}

${ }^{a}$ Intact seeds were extracted sequentially with $0.2 \%$ ammonium oxalate, $0.2 \mathrm{~N}$ $\mathrm{NaOH}$ and $2 \mathrm{~N} \mathrm{NaOH}$, neutralized, and assayed by the phenol-sulfuric acid method against glucose standards. The results are shown as $\mu \mathrm{g} / \mathrm{mg}$ of seeds. Analyses were performed in triplicate and results are given as $\mu \mathrm{g} / \mathrm{mg}$ seed \pm SE. All genotypes were grown, harvested, and stored together. Letters ' $b$ ' ' $c$ ' and ' $\mathrm{d}$ ' denote a significantly difference from the wild type (Dunnett's test, $P<0.05 ; P<0.01 ; P<0.001$ respectively)

\section{Discussion}

GALT2-GALT6 encode Hyp-GALTs for AGPs and are widely expressed in Arabidopsis

Bioinformatic approaches were previously used to identify a small, six-membered gene family within the GT 31 family of the CAZY database as potential candidates for encoding Hyp-O-GALTs for AGPs [15, 18, 42]. Protein members of this family were designated GALT1-GALT6 and distinguished by the presence of a GALT domain as well as a GALECTIN domain. Previously, GALT1 was shown to catalyze galactose addition for formation of the Lewis a epitope on $N$-linked glycans [24], while GALT2 and GALT5 were shown to act as Hyp-GALTs specific for AGPs $[15,16]$. In this study, biochemical and genetic evidence indicates that GALT3, GALT4, and GALT6 also act as Hyp-GALTs for AGPs.

Heterologous transient expression of GALT1-GALT6 in tobacco epidermal cells demonstrated a significant increase in Hyp-GALT activity compared with various tobacco control plants, with the notable exception of GALT1 (Fig. 1 and Additional file 1: Table S4). The absence of Hyp-O-GALT activity over background levels in case of GALT1 is consistent with its reported, nonAGP related function and provided a useful control for the studies reported here [24]. Moreover, this transient expression study in tobacco corroborates previous findings that GALT2 and GALT5, which were expressed in
Pichia pastoris, act as AGP-specific Hyp-GALTs [15, 16]. It should be noted that the amount of activity detected in these two heterologous expression systems varied; the tobacco system showed much higher levels of activity than the Pichia system, even when taking into account the higher level of endogenous activity associated with the tobacco system. This observation could be explained by the need for other plant-based proteins or factors to enhance or optimize Hyp-O-GALT activity.

Substrate specificity of GALT2-GALT6 was investigated using various potential acceptor substrates and demonstrated that GALT2-GALT6 is specific for model AGP sequences (Fig. 2). These findings are consistent with the Hyp contiguity hypothesis, which states that clustered, non-contiguous Hyp residues are sites of AG addition, whereas contiguous Hyp residues are sites for the addition of Ara oligosaccharides [43, 44]. Despite the higher enzyme activity observed in the transient tobacco expression system compared to Pichia, the same sizedependent preference for AGP substrates was observed for GALT2 and GALT5 in both systems, where $[\mathrm{AO}]_{7}$ was the preferred substrate [16]. GALT3, GALT4, and GALT6 also acted in a similar manner within the tobacco system.

Heterologous transiently expressed GALT2-GALT6 in tobacco microsomes have similar biochemical properties to the GALT(s) present in Arabidopsis microsomal membranes and to GALT2 and GALT5 expressed in Pichia, specifically all require UDP-Gal as the sugar donor $[15,16,45,46]$. They have a requirement for $\mathrm{Mn}^{2+}$ followed by $\mathrm{Mg}^{2+}$ for their optimal activity, in contrast to $\mathrm{Mg}^{2+}$ followed by $\mathrm{Mn}^{2+}$ in Pichia microsomes.

Genetic mutant analysis provides additional in vivo evidence that GALT3, GALT4, and GALT6 function as Hyp-GALTs, similar to GALT2 and GALT5 (Tables 1 and 2). Allelic galt knock-out mutants for all these genes exhibit reduced (i.e., 15-35 \% less) Hyp-GALT activity and contain considerably less (i.e., 10-60\% less) glycosylated (i.e., $\beta$-Gal-Yariv precipitiable) AGPs. In addition, AGP profiling of the galt3, galt4, and galt6 mutants extends these findings and indicates that their activity is not limited to a particular AGP or a small subset of AGPs, but instead broadly acts on coexpressed AGPs, similar to that previously reported for galt2 and galt5 mutants (Additional file 1: Figure S7).

qRT-PCR analysis of GALT1-GALT6 was performed to examine their expression patterns and provide information relevant to phenotypic analysis of their corresponding allelic mutants (Fig. 3). All six genes were widely expressed, and in the cases of GALT2-GALT6 are consistent with the widespread distribution of AGPs and the multiple functions associated with them. These patterns were corroborated by searching public expression databases, which revealed even broader organ and tissue 

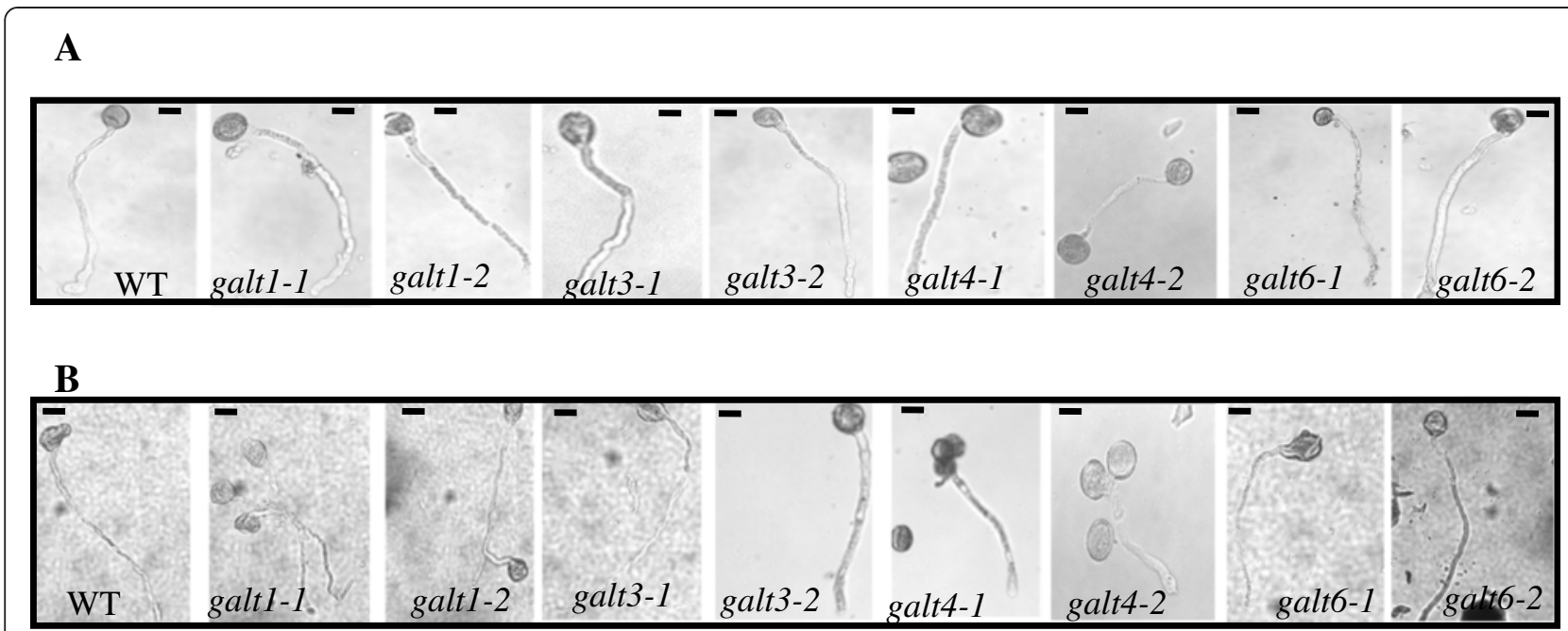

\section{C}

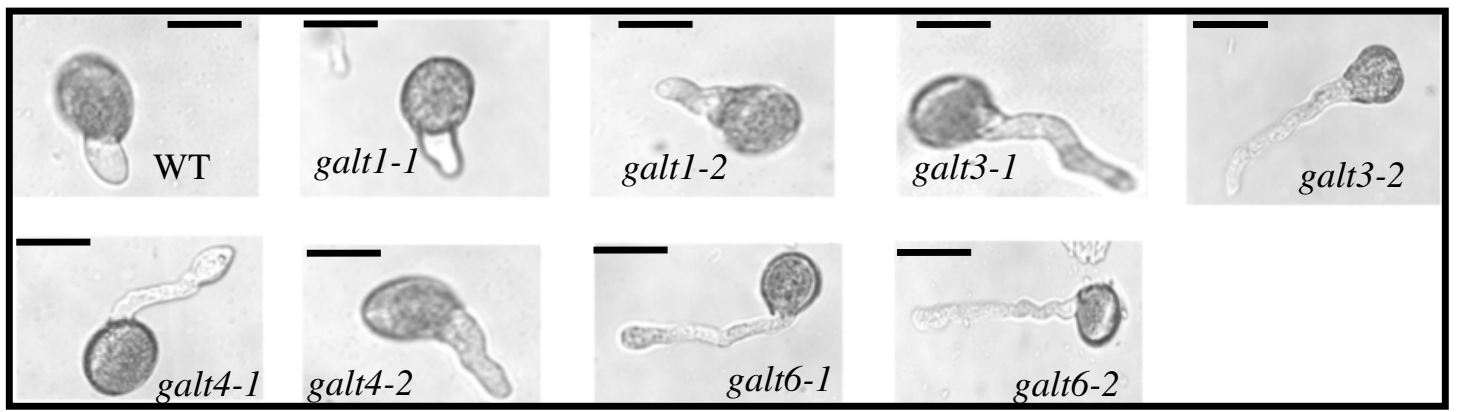

D

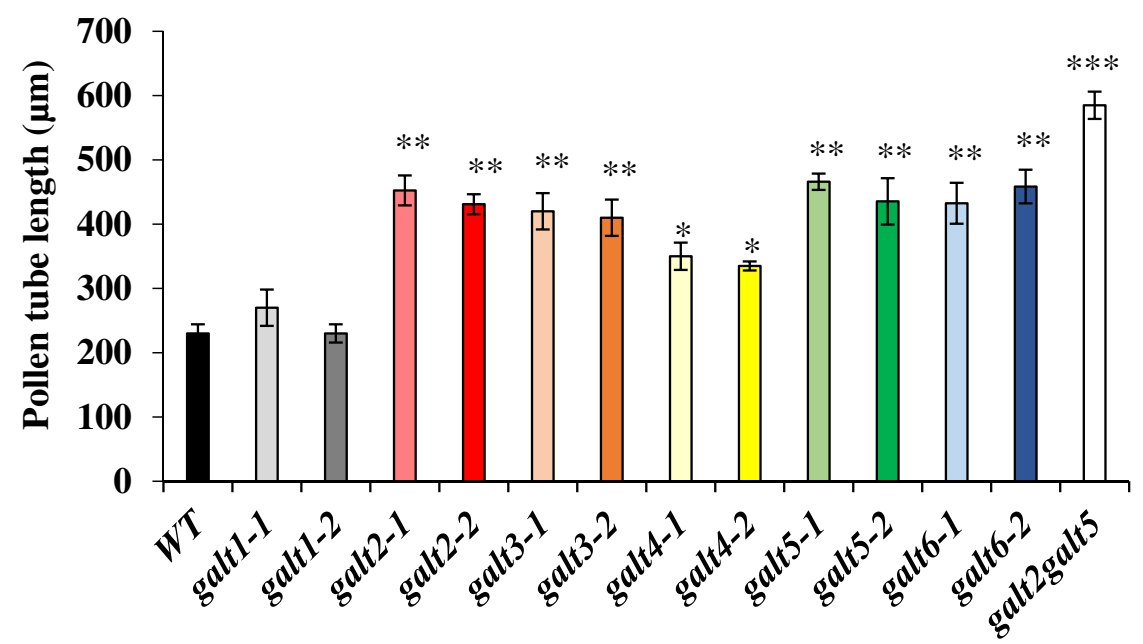

Fig. 9 The galt single mutants demonstrate reduced inhibition of pollen tube growth in the presence of $\beta$-Gal-Yariv reagent. a Representative images of pollen tubes from WT, galt1, galt3, galt4, and galt6 mutants after $16 \mathrm{~h}$ in pollen germination medium, and $\mathbf{b}$ in pollen germination medium supplemented with $30 \mu \mathrm{M}$ a-Gal-Yariv, and $\mathbf{c}$ in pollen germination medium supplemented with $30 \mu \mathrm{M} \beta-G a l-Y a r i v$ reagent. Bar = 50 $\mu \mathrm{m}$. d Pollen tube lengths from WT, galt1-galt6 mutants, and galt2galt5 double mutants were measured over $16 \mathrm{~h}$ in the pollen germination medium supplemented with 30 MM $\beta$-Gal-Yariv reagent. Twenty flowers from each genotype and 25 pollen tubes from each flower were measured using Image $\mathrm{J}$ software. The experiment was done in triplicate, and the asterisks indicate mean values significantly different from the WT (Dunnett's test, ${ }^{*} P<0.05$; **P $<0.01 ; * * * 0<0.001)$ 


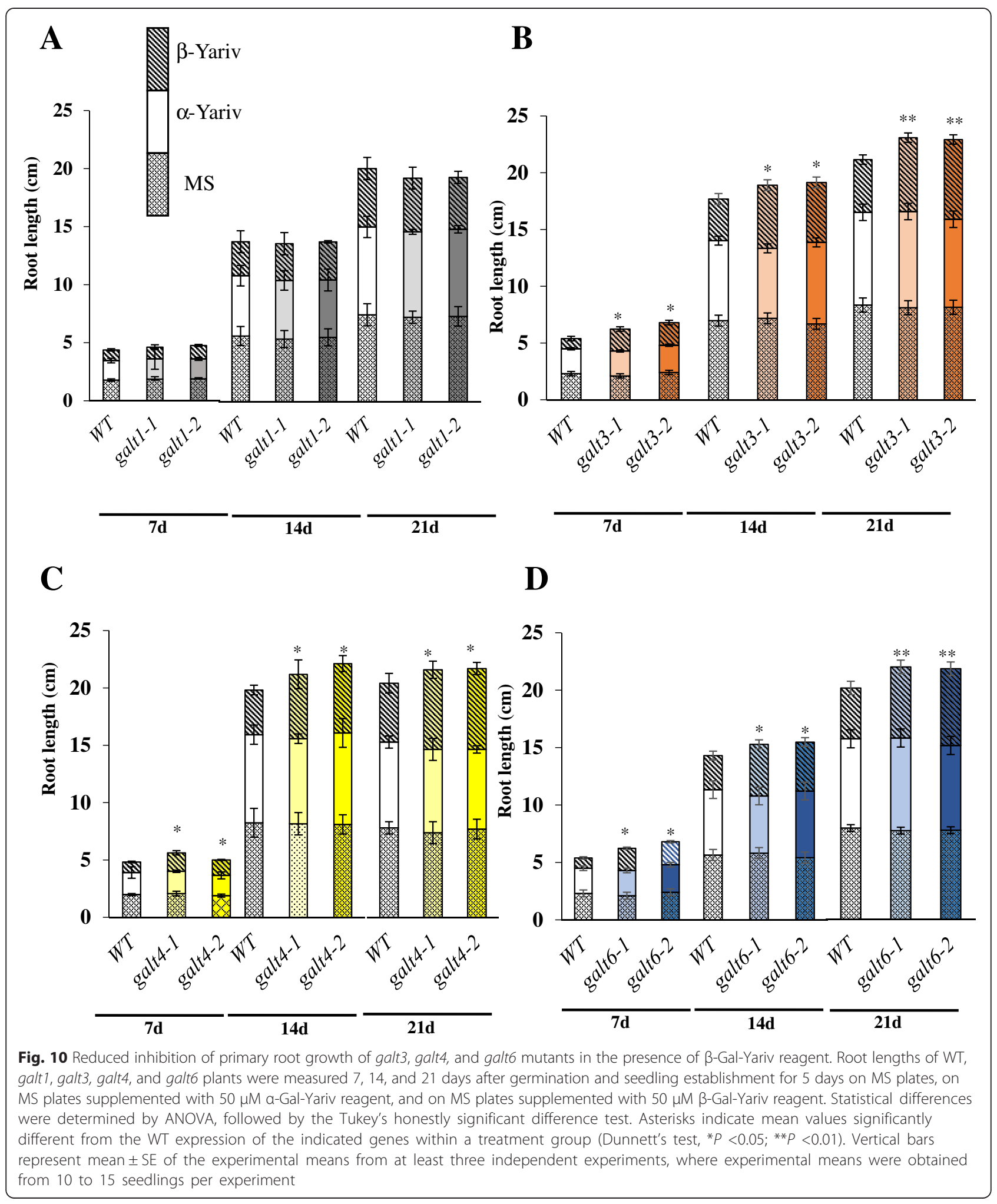

expression patterns (Additional file 1: Figure S4). HPGT1HPGT3, three recently identified Hyp-O-GALTs for AGPs that lack GALECTIN domains, were also included in this analysis and showed equally broad patterns of gene expression [17]. Nonetheless, within a given organ or tissue, the Hyp-O-GALT genes exhibit both temporal and spatial differences in their expression patterns. Transcriptome analyses using RNA extracted from laser-capture 


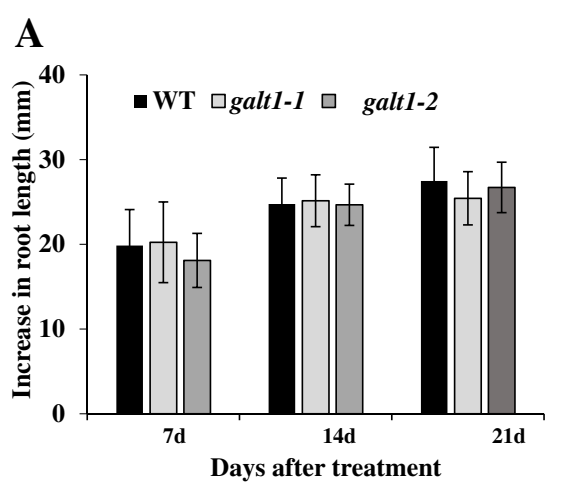

C

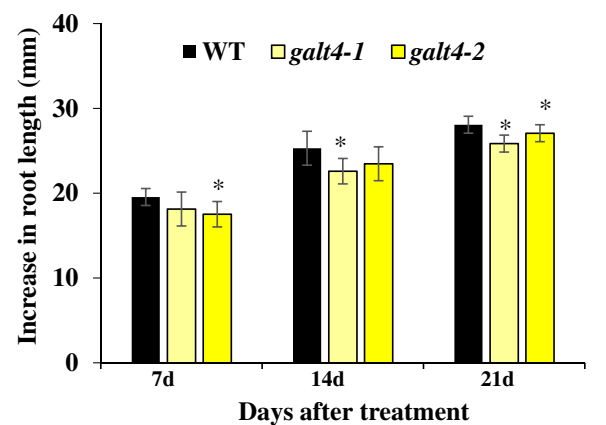

B

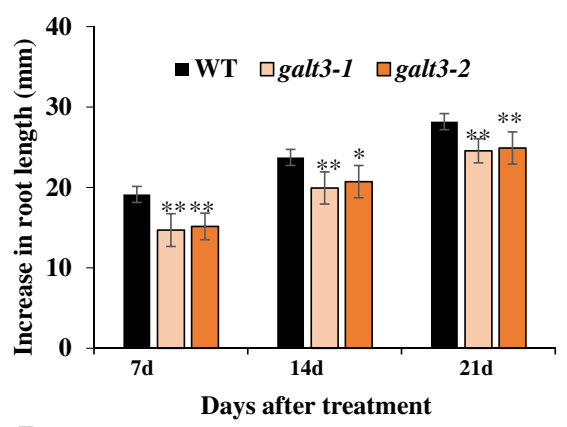

D

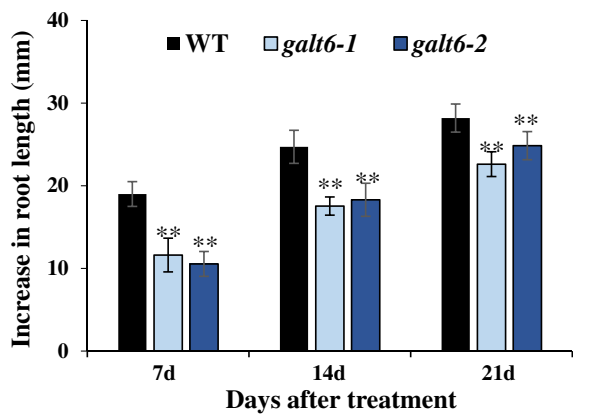

Fig. 11 Salt-induced inhibition of primary root elongation in galt3, galt4, and galt6 mutants. Five-day-old WT, galt1, galt3, galt4, and galt6 seedlings germinated on MS medium were transferred onto media containing $100 \mathrm{mM} \mathrm{NaCl}$ and grown vertically. Root elongation (i.e., increase in length after transfer) was measured after 7, 14, and 21 days of growth in the non-permissive media. Data are the means \pm SE of measurements from five independent experiments (total $n=100$ ). Asterisks indicate mean values significantly different from the WT (Dunnett's test, $* P<0.05 ; * * P<0.01$ )

dissected seed coat tissue [36] provides a particularly striking illustration of the diverse tissue-specific expression patterns of GALT2-GALT6 and HPGT1-HPGT3 (Additional file 1: Figure S5).

\section{GALT3, GALT4, and GALT6 are localized to Golgi vesicles} Various approaches have indicated that AGP glycosylation occurs in Golgi vesicles. These approaches include bioinformatics predictions using Signal P and Golgi Predictor, biochemical experiments on hydroxyproline-rich glycoprotein (HRGP) biosynthesis [25, 45-49], a proteomics technique for localization of organelle proteins by isotope tagging [49], and localization studies performed with other AGP GTs, including GALT2, GALT5, HPGT1HPGT3, AT1G77810, GALT31A, GALT29A, GlcAT14A, and FUT6 [12, 15, 16, 18, 19, 21]. Given their similarity to GALT2 and GALT5 and their demonstrated Hyp-GALT activity, GALT3, GALT4, and GALT6 were expected to reside in the Golgi vesicles, and this was confirmed by heterologous expression of fluorescently tagged protein fusions in tobacco leaves (Fig. 4). Interestingly, only GALT2 is found in both the ER and Golgi, indicating that Hyp-galactosylation may be initiated in the ER, but completed in the Golgi where the bulk of the Hyp-O-GALTs are located [15].
GALT mutant phenotypes reveal functional roles of AGP glycosylation in normal growth and development

Genetic mutant analysis was used to investigate and compare the in vivo functional contributions of AGP glycosylation by GALT3, GALT4, and GALT6 with that of GALT2 and GALT5 (Fig. 5; Additional file 1: Table S1). To date, a variety of functions are attributed to certain AGPs or GTs acting on AGPs based on mutant analysis; these mutants show embryo lethality, conditional defects of primary root growth, cell elongation, and pollen tube growth (Additional file 1: Table S5) [13, 14, 16, 17, 19, 21, 23]. Like galt2 and galt5, galt3, galt4, and galt6 single mutant lines showed subtle or no detectable growth phenotypes under normal soil-based growth conditions, which is likely attributed to the functional redundancy within the GALT2-GALT6 gene family $[15,16]$. The phenotypes that were displayed by the single mutants here included reduced root hair length and/or density for galt3, galt4, and galt6 (Fig. 6), reduced seed set for galt4 and galt6 (Fig. 7; Table 3), reduced adherent seed mucilage for galt3, and galt6 (Fig. 8 and Table 4), and accelerated leaf senescence for galt6 (Additional file 1: Figure S9). Although these phenotypes are consistent with the expression profiles of these genes, it would be difficult to predict such phenotypes from expression data alone. It is anticipated that 
double and multiple galt mutants will show more pronounced mutant phenotypes, as was the case when galt2galt 5 double mutants were produced and characterized [16].

With respect to root hair length and density, knockout mutants of GALT3 and to a lesser extent GALT6 and GALT4, displayed shorter and/or less dense root hairs, indicating glycosylated AGPs play a role in tip growth of root hairs in Arabidopsis (Fig. 6). The galt2, galt5, and galt2galt5 double mutants also demonstrate this response and were used here as positive controls [16]. Reduced density of root hairs can be attributed to an increase in longitudinal length of epidermal cells and/or to a decrease in the number of root hair-forming cells leading to the formation of less root hairs $[50,51]$. Other studies, using $\beta$-Gal-Yariv reagent and prolyl hydroxylase genetic mutants, have also indicated that HRGPs (i.e., AGPs and extensins) are involved with root hair growth [52-55].

With respect to seed mucilage, galt3 and galt6 mutants display the most significant decrease in the width of the adherent seed mucilage layer, along with galt 2 and galt5 upon staining with ruthenium red when compared to WT seeds, which indicates that glycosylated AGPs are involved in maintaining the adherent mucilage layer in seeds (Fig. 8, Tables 4 and 5). The galt2galt5 double mutants also demonstrate this response and were used here as positive controls [16]. Harpaz-Saad et al. [37] reported that both $F E I 2$, a cell wall leucine-rich receptor-like kinase and SOS5, a fasciclin like AGP are critical for the synthesis and proper deposition of cellulosic rays in seed coat mucilage, which coincides with an increase in solubility of the pectinaceous component of seed coat mucilage. The GALT6 expression profile during seed coat differentiation is identical to that of FEI2. Moreover, GALT6 is expressed at a higher level during late embryogenesis compared to the early embryogenesis stages, consistent with its involvement with seed coat development and in seed coat mucilage adherence. Taken together, GALT6, GALT3, GALT2 and GALT5 likely glycosylate AGPs, like SOS5, that are essential for maintaining mucilage adherence in seeds during hydration.

With respect to seed set, galt4 and galt6 mutants phenocopied knock-out mutants of two pollen-specific AGPs genes, AGP6 and AGP11, in terms of reduction in number of seeds per silique, but not in abnormal pollen structures, although occasionally some collapsed pollen were observed in galt4 and galt6 mutants (Fig. 7, Table 3, Additional file 1: Figure S8) This suggests GALT4 and GALT6 may be involved in glycosylation of pollen -specific AGPs. Several studies have indicated that AGPs play key roles in pollen biogenesis, pollen tube growth and development, pollen tube guidance, and pollen-pistil interactions during post pollination events [56-61].
Indeed, a number of AGP genes are reported to show pollen-specific expression in Arabidopsis, including AGP6, AGP11, AGP23, and AGP40. Reciprocal crosses of the mutants with WT confirmed that genetic transmission of this phenotype is contributed by the male gametophyte (Fig. 7 and Table 3). In contrast, it is interesting to note that AGP18 is reported to be essential for female gametogenesis, given that functional megaspores in RNAi plants fail to enlarge and divide, resulting in ovule abortion and reduced seed set [62].

With respect to leaf senescence, galt6 mutants displayed age-dependent early onset of leaf senescence, indicating AGP glycosylation is related to plant aging (Additional file 1: Figure S8 and Table 2). Several lines of evidence implicate the involvement of AGPs in regulating programmed cell death and senescence [63-67]. For example, $\beta$-Gal-Yariv treatment is known to promote programmed plant cell death, while overexpressing AGPs results in tomato plants with enhanced lifespans [67]. In this context, it is noteworthy that GALT6 is highly expressed in senescing leaf tissue and that only galt6 mutants demonstrate a significant reduction in the $\beta$-GalYariv precipitable AGPs in senescent leaves (Additional file 1: Figure S4 and Table 2).

Any one defect leading to reduced AG glycosylation is likely to impair the function of multiple AGPs, leading to pleiotropic effects as observed here. At least some of the genes involved in AGP glycosylation, however, exist in small redundant or partially redundant genes families and may compensate for one another when a given gene in the family is knocked out [12, 15-17, 21, 22]. In some cases, aberrant phenotypes may not be discernable under normal conditions, but may be revealed under suboptimal growth conditions.

\section{Conditional phenotypes indicate GALT3, GALT4, and GALT6 function in tip growth}

The galt3, galt4, and galt6 mutants display several conditional pollen and root phenotypes in response to $\beta$-GalYariv treatment or salt treatment similar to those observed in galt2 and galt5 single mutants as well as galt2galt5 double mutants [16]. In both pollen tubes and roots, $\beta$ Gal-Yariv treatment is known to bind AGPs, specifically to their $\beta$-1,3-galactan chains, and inhibit pollen tube and root elongation [68-71] indicating AGPs are important for such growth. This inhibition is alleviated in single mutants, which have reduced AGP glycosylation due to the lack of respective GALTs (Figs. 9, 10, Additional file 1: Figure S10 and Figure S11). Under normal conditions (i.e., without $\beta$-Yariv treatment), no inhibition is observed in the single mutants, most likely due to gene redundancy, a conclusion supported by the observation that galt2galt 5 double mutants show inhibition under normal conditions [16]. Thus, GALT3, GALT4, and GALT6, like GALT2 and 
GALT5, are important for pollen tube and root growth and indicate that the AG polysaccharides are required for these growth functions.

In roots, salt treatment results in reduced root growth, which can be measured directly or by the root bending assay, which is commonly used to screen plants or mutants for salt sensitivity. Here, galt3, galt4, and galt6 mutants display salt hypersensitive root growth in both of these assays (Fig. 11). Thus, GALT3, GALT4, and GALT6, like GALT2 and GALT5, function in root growth and indicate the importance of AG polysaccharides in this process. GALT3, GALT4, and GALT6, like GALT2 and GALT5, also function to prevent root tip swelling in response to salt stress (Additional file 1: Figure S13 and Figure S14). Since SOS5, a fasciclin-like AGP, and FEI1 and FEI2, two cell wall receptor-like kinases, also prevent such root tip swelling, and are in the same genetic pathway as GALT2 and GALT5, it appears that AGP glycosylation via any of the five GALTs (GALT2-GALT5) likely generates a carbohydrate signal on SOS5, which is detected and transduced by the FEI1/ FEI2 kinases to promote cell wall integrity $[16,72,73]$.

\section{Conclusions}

In conclusion, biochemical and genetic evidence presented here indicates that GALT3, GALT4, and GALT6, like GALT2 and GALT5, function as AGP-specific HypGALTs. The largely, but not completely, overlapping pleiotropic effects observed in genetic null mutants for each of the genes with respect to multiple aspects of plant growth, development, and reproduction indicate the importance of AG polysaccharides to the functions of AGPs. Thus, these Hyp-GALT genes function in a largely redundant manner, and it is anticipated that more severe biochemical and physiological phenotypes will occur when multiple genetic mutants are studied, revealing additional AGP functions. Indeed, future work aimed at examining such multiple mutants, the role of the GALECTIN domain, the potential for enzyme complex formation between and among Hyp-GALTs and other GTs involved with AGP biosynthesis, Hyp-GALT/ AGP trafficking, and the potential signaling roles of AG polysaccharides will provide deeper insight to the evolution and biology of this small enzyme family and the AGP family members that serve as their substrates.

\section{Methods}

In silico analysis of the six-membered GALT family

Protein sequences from GALT1, GALT3, GALT4 and GALT6 were run through several prediction programs (TMHMM 2.0, TargetP 1.1, SignalP v2.0.b2 server) to obtain information on their putative subcellular localization and topology [25, 26, 74]. Hydrophobic cluster analysis
(HCA) plots were obtained from the drawhca server on the Internet (http://bioserv.impmc.jussieu.fr/hca-seq.html) and were analyzed as described by Breton et al. [75]. The coexpression network for the GT31 member genes was illustrated using the program GENEMANIA (www.genemania.org) using GALT2 and GALT5 as query genes.

\section{Plant lines and plant growth conditions}

Arabidopsis thaliana accession Columbia-0 (Col-0) and two T-DNA insertion lines for At1g26180-(galt1-1, Sail_170_A08 and galt1-2, Salk_006871), At3g06440 (galt31, Salk_085633 and galt3-2, Salk_005178), At1g127120 (galt4-1, Salk_136251 and galt4-2, Salk_131723), and At5g62620 galt6-1, Sail_59_D08 and galt6-2, Sail_70_B02) were obtained from the Arabidopsis Biological Resource Center (ABRC, Ohio State University). All plants used in this study were germinated after 4 days of stratification in the dark at $4{ }^{\circ} \mathrm{C}$ and were grown under long-day conditions ( $16 \mathrm{~h}$ of light $/ 8 \mathrm{~h}$ of dark, $22{ }^{\circ} \mathrm{C}, 60 \%$ humidity) in growth chambers or growth rooms. Sequencing of the amplified PCR products from the mutant plants led to the accurate determination of the T-DNA insertion site.

\section{Mutant confirmation by PCR and RT-PCR}

Genomic DNA was isolated from leaves of the mutants and WT plants and was extracted using the $2 \times$ CTAB method described by Murray and Thompson [76]. Subsequent PCR analysis was carried out using gene specific primers in conjunction with the T-DNA primers. The primer locations are indicated in Fig. 4, and the corresponding primer sequences are listed in Additional file 1: Table S6. For sequencing, PCR products were purified by gel extraction (Wizard ${ }^{\circ}$ SV Gel and PCR Clean-Up System, Promega, Madison, WI, USA) and sequenced by the Ohio University Genomics Facility (http:// www.dna.ohio.edu/). To analyze transcript levels of GALT1, GALT3, GALT4, and GALT6, total RNA was isolated from 2 week old seedlings of WT and mutant plants. For tissue specific expression profiling, tissue was harvested at different growth stages as defined by Boyes et al. [77]. In both cases, RNA was extracted using Trizol (Life Technologies, Grand Island, NY, USA) and Direct-zol $^{\text {max }}$ RNA MiniPrep kit (Zymo Research, Irvine, CA, USA). First-strand cDNA synthesis was performed from $2 \mu \mathrm{g}$ of total RNA using oligo-dT (Coralville, Iowa) and GoScript reverse transcriptase (Promega, Madison, WI, USA). RT-PCR was performed using OneTaq DNA polymerase (New England Biolabs, Ipswich, MA, USA) and gene-specific RT primers (Additional file 1: Table S6). The number of amplification cycles was 28 to evaluate and quantify differences among transcript levels before the reaction reached saturation. 
For quantitative real-time PCR (qRT-PCR), cDNAs were amplified using Brilliant II SYBR Green qRT-PCR Master Mix with ROX (Agilent Technologies, La Jolla, CA, USA) in an MX3000P real-time PCR instrument (Agilent Technologies). PCR was optimized and reactions were performed in triplicate. The transcript level was standardized based on cDNA amplification of ubiquitin 10 (UBQ10, At4g05320) as a reference. Primer sequences are listed in Additional file 1: Table S6.

\section{Heterologous expression of GALT1, GALT3, GALT4, and GALT6 and Hyp-GALT activity assay}

Coding regions of GALT1, GALT3, and GALT4 were obtained from the RIKEN Bioresource Center, while the coding region of GALT6 was obtained from The French Plant Genomic Resource Center (http://cnrgv.toulouse. inra.fr/). N-terminal $6 \mathrm{x}$-His tag fusion gene constructs were amplified using Q5 high fidelity DNA Taq polymerase (New England Biolabs, Ipswich, MA, USA), initially cloned into the pENTR/D-TOPO vector (Life technologies, Grand Island, NY, USA), and eventually cloned into the destination vector pMDC32 gateway vector using LR clonase enzyme mix (Life Technologies Grand Island, NY, USA). Primers used for amplification are listed in Additional file 1: Table S6. Gene constructions were transformed into Agrobacterium strain GV3101 by the freeze thaw method, and the transformants were grown overnight in Luria-Bertani (LB) medium. Bacterial cells were harvested by centrifugation and suspended in a buffer containing $10 \mathrm{mM}$ MES, $10 \mathrm{mM} \mathrm{MgCl}$, and $50 \mu \mathrm{M}$ acetosyringone $\left(\mathrm{OD}_{600}=0.2\right)$. Leaves from 6week-old WT N. tabacum cv. Petit Havana were used for Agrobacterium-mediated transient expression. Four days after infiltration, leaves were harvested, and microsomes were prepared according to the method described by Liang et al. [45] with minor modifications.

\section{Fluorescent protein fusion and subcellular localization}

Full length GALT3, GALT4, and GALT6 devoid of stop codons was cloned into the pENTR/D-TOPO vector (Life technologies, Grand Island, NY, USA) and sequenced. The resulting plasmids were cloned in the destination vector pEarlyGate 101 by a gateway cloning strategy, using LR clonase enzyme mix (Life Technologies Grand Island, NY, USA) to generate the YFP Nterminal fusion constructs. These gene constructions were transformed into Agrobacterium strain GV3101 and infiltrated into tobacco leaves as described in the above section except that the bacterial concentration was lower $\left(\mathrm{OD}_{600}=0.05\right)$. The GALT3-YFP, GALT4-YFP, and GALT6-YFP constructions were co-expressed with either the ER marker HDEL-GFP or the Golgi marker sialic acid transferase (ST)-GFP to ascribe subcellular localization. Transformed plants were incubated under normal growth conditions and imaged 2 days postinfiltration using an upright Zeiss LSM 510 META laser scanning microscope (Jena, Germany), with a $40 \times$ oil immersion lens and an argon laser. For imaging the expression of YFP constructs, the excitation line was $514 \mathrm{~nm}$, and emission data were collected at 535-590 nm; whereas for GFP constructs, the excitation line was $458 \mathrm{~nm}$, and the emission data were collected at 505$530 \mathrm{~nm}$.

GALT assay with microsomal preparations from transiently expressed GALT1, GALT3, GALT4, and GALT6 in tobacco epidermal cells

The standard GALT reaction was performed as described in Basu et al. [15] using detergent permealized microsomes from transiently expressed GALT1, GALT3, GALT4, and GALT6. Three permeabilized microsomal membranes were included as controls, one from the WT tobacco leaves, one from WT tobacco leaves infiltrated with Agrobacterium GV3101 transformed with the empty expression vector (pMDC32), and one with tobacco leaves infiltrated with ST-GFP constructs as negative controls.

\section{Purification of Hyp-GALT reaction products by reverse-phase HPLC}

The GALT reaction products were purified by RP-HPLC as described by Liang et al. [45].

\section{Determination of substrate specificity for GALT2-GALT6}

Microsomal fractions from tobacco leaves expressing GALT2-GALT6 constructs were used for determination of substrate specificity as described by $[15,16]$.

Isolation of Golgi-enriched plant microsomal membranes Plant microsomal membranes were extracted from WT, galt1-1, galt1-2, galt3-1, galt3-2, galt4-1, galt4-2, galt6-1 and galt6-2 according to Liang et al. [45] with minor modifications.

\section{Extraction of AGPs}

AGPs were extracted from the WT, galt1-1, galt1-2, galt3-1, galt3-2, galt4-1, galt4-2, galt6-1, and galt6-2 mutant plants as described by Schultz et al. [78] precipitated and quantified as described by Gao et al. [79] and Yariv et al. [80]. AGP profiling was conducted as described by Youl et al. [81] with modifications. AGPs were obtained from $8 \mathrm{~g}$ of plant material, precipitated by $\beta$-Gal - Yariv reagent and dissolved in $1 \mathrm{ml}$ of deionized water before applying $100 \mu \mathrm{l}$ onto a polymeric reversephase column (PRP-1, $5 \mu \mathrm{m}, 4.1 \times 150 \mathrm{~mm}$; Hamilton) equilibrated with buffer A (0.1\% trifluoroacetic acid). Fifty $\mu \mathrm{g}$ of $[\mathrm{AO}]_{7}$ was used as a control to monitor the retention time of a pure AGP peptide. Samples were eluted from the column following a linear gradient with 
solvent B ( $0.1 \%$ trifluoroacetic acid in $80 \%$ acetonitrile): $0-30 \%$ solvent B in $30 \mathrm{~min}$, then $30-100 \%$ in $30 \mathrm{~min}$ at a flow rate of $0.5 \mathrm{ml} / \mathrm{min}$. Chromatography was monitored by absorption at 215 and $280 \mathrm{~nm}$.

AGPs from siliques, flowers, inflorescence stem, and senescent leaves were extracted as described by Lamport [82], with minor modifications. To extract AGPs from siliques ( $2.5 \mathrm{~g})$, flowers (1.5 g), inflorescence stems ( $5 \mathrm{~g})$, and senescent leaves $(5 \mathrm{~g})$, they were ground to a fine powder in liquid nitrogen. Ground tissue was added to an extraction buffer of $\mathrm{CaCl}_{2}(2 \% \mathrm{w} / \mathrm{v})$ at a volume of $2 \mathrm{ml}$ for each gram of tissue, and stirred for $3 \mathrm{~h}$ at room temperature. Samples were centrifuged for $30 \mathrm{~min}$ at $10,000 \mathrm{~g}$ at room temperature. The supernatant was freeze-dried overnight and resuspended in $1 \mathrm{ml}$ of $2 \%$ $\mathrm{CaCl}_{2}$ and transferred to $2 \mathrm{ml}$ microcentrifuge tubes. AGPs were precipitated overnight at $4{ }^{\circ} \mathrm{C}$ with an equal volume of the $\beta-\mathrm{Gal}$ - Yariv reagent $(2 \mathrm{mg} / \mathrm{m}$ in $2 \% \mathrm{w} / \mathrm{v}$ $\mathrm{CaCl}_{2}$ ). The insoluble $\beta$-Gal-Yariv-AGP complex was collected by centrifugation at $10,000 \mathrm{~g}$ in a microcentrifuge for $1 \mathrm{~h}$. The $\beta$-Gal-Yariv was removed by washing the pellet three times in $2 \%(\mathrm{w} / \mathrm{v}) \mathrm{CaCl}_{2}$ and then twice in methanol. The pellet was dried, dissolved in $100 \mu \mathrm{l}$ of water mixed with $25 \mathrm{mg}$ of solid sodium dithionite and incubated for $30 \mathrm{~min}$ at $50{ }^{\circ} \mathrm{C}$ until the mixture decolorized. The resulting solution was then desalted on a PD10 column (Pharmacia) that had been equilibrated with water, and the eluate was freeze-dried.

\section{Evaluation of seed set}

Mature siliques from 6-week old WT, galt1, galt3, galt4, and galt6 plants were collected, and silique length and weight were measured. For seed number, siliques were decolorized by incubation in $100 \%$ ethanol at $37{ }^{\circ} \mathrm{C}$ overnight before dissection of the siliques. For reciprocal cross-pollinations, 10 flowers from WT, galt4-1, galt4-2, galt6-1, and galt6-2 were selected at stage 12. These flowers were emasculated before pollinating them with fresh pollen obtained from flowers at stage 13. After 10 days, siliques were collected from these flowers to examine seed set.

\section{Root growth measurements}

For monitoring root growth in response to $\beta$-Gal-Yariv reagent, WT, galt1-1, galt1-2, galt3-1, galt3-2, galt4-1, galt4-2, galt6-1 and galt6-2 seedlings were grown on MS plates for 7 days before they were transferred to MS plates supplemented with $50 \mu \mathrm{M} \alpha$-Gal-Yariv reagent or $50 \mu \mathrm{M} \beta$-Gal-Yariv reagent. For seedling growth in salt, 7-day-old seedlings of WT, galt1-1, galt1-2, galt3-1, galt3-2, galt4-1, galt4-2, galt6-1, and galt6-2 were transferred to MS medium containing $1 \%$ agar and $100 \mathrm{mM}$ or $150 \mathrm{mM} \mathrm{NaCl}$. Root length was determined on lowmagnification $(\times 10)$ digital images captured using a CCD camera and image analysis freeware (Image); http:// rsb.info.nih.gov/ij/). For analysis of salt hypersensitivity of the mutant plants, root growth was monitored using a root bending assay [83], and images were taken using a Nikon SMZ1500 stereomicroscope coupled with a CCD Infinity 2 camera and analysis software.

\section{In vitro pollen germination assay}

Flowers collected from WT, galt1-1, galt1-2, galt3-1, galt3-2, galt4-1, galt4-2, galt6-1, and galt6-2 plants 1 to 2 weeks after bolting were used for the examination of pollen tube phenotypes. Individual open flowers were germinated in vitro as described by Boavida and McCormick [84], on solid germination medium $\left(0.01 \% \mathrm{H}_{3} \mathrm{BO}_{3}, 1 \mathrm{mM}\right.$ $\mathrm{MgSO}_{4}, 5 \mathrm{mM} \mathrm{KCl}, 5 \mathrm{mM} \mathrm{CaCl}_{2}, 10 \%$ sucrose, and $1.5 \%$ low-melting agarose, $\mathrm{pH} 7.5$ and $30 \mu \mathrm{M} \beta$-Gal-Yariv reagent or $30 \mu \mathrm{M} \alpha$-Gal-Yariv reagent) at $22{ }^{\circ} \mathrm{C}$ and $100 \%$ humidity in the dark. Pollen tube germination rates were calculated by dividing the total number of germinated tubes by the number of grains. Images and measurements of pollen tubes were done at $20 \times$ magnification in a Nikon Phot-lab2 microscope coupled with a SPOT RT color CCD camera and SPOT 4.2 analysis software.

\section{Aberrant root hair morphology}

Root hair length from 8-day-old plants grown on agar plates was determined on low-magnification $(\times 10)$ digital images captured using a CCD camera and image analysis freeware (ImageJ; http://rsb.info.nih.gov/ij/). To ensure comparable results, the area $3-5 \mathrm{~mm}$ behind the root tip was analyzed. Plants grown on agar plates were carefully removed in $100 \mu \mathrm{l}$ of half-strength MS medium on microscope slides for analysis. Quantification of root hairs length and density was performed using 10 seedlings for each genotype, and 25 root hairs from each root were measured.

\section{Cytochemical staining of seeds and determination of adherent mucilage size and mass}

Seeds of all the indicated genotypes were prehydrated in water and stained with $0.01 \%$ ruthenium red. The staining was performed as described by Willats and Knox, [85] and Harpaz-Saad et al. [37]. Imaging was done using a Zeiss LSM 510 confocal microscope. The volume of adherent mucilage was measured using the method described by Yu et al. [86].

\section{Alexander's staining of pollen}

To examine pollen viability, anthers were removed from flowers, and mounted on microscope slides, and stained with Alexander's stain as described by Alexander [87]. 


\section{Leaf senescence assay}

Leaf 7 was marked as 18 DAG (days after germination) and sampling started at 19 DAG and continued every other day until full senescence was reached (39 DAG) as described by Breeze et al. [88]. Because the age of a leaf can affect its response to factors that influence senescence, plants of indicated genotypes were taken from synchronously growing populations, and only identically aged leaves were pooled for chlorophyll and protein content measurements.

\section{Measurement of chlorophyll content}

Chlorophyll was extracted from WT, galt6-1, and galt6-2 leaves by immersion in $1 \mathrm{ml}$ of $\mathrm{N}, \mathrm{N}$-dimethylformamide for $48 \mathrm{~h}$ in the dark at $4{ }^{\circ} \mathrm{C}$. Absorbance was recorded at 664 and $647 \mathrm{~nm}$, and total chlorophyll concentration was calculated as described by Xiao et al. [89]. The total chlorophyll content was measured and normalized per gram fresh weight of sample.

\section{Cell wall preparation}

One-hundred milligram of WT and galt mutant seeds were extracted sequentially with $0.2 \%$ ammonium oxalate, 0.2 and $2 \mathrm{~N}$ sodium hydroxide for $1 \mathrm{~h}$ each with vigorous shaking at $37{ }^{\circ} \mathrm{C}$. Both sodium hydroxide extractions were neutralized with acetic acid. Total sugar $(\mu \mathrm{g} / \mathrm{mg}$ seed) was determined with a phenol-sulfuric assay based on Dubois et al. [90]. In short, $200 \mu \mathrm{l}$ of resuspended extract was incubated with $100 \mu \mathrm{l}$ freshly made $5 \%(\mathrm{v} / \mathrm{v})$ aqueous phenol and $1 \mathrm{ml}$ concentrated sulfuric acid for $2 \mathrm{~h}$ at $30{ }^{\circ} \mathrm{C}$. Absorbance was detected at $500 \mathrm{~nm}$ against glucose standards of $0.5,2.5,5,7.5$, $10,15,25 \mu \mathrm{g}$ for which a linear response curve was obtained.

\section{Statistical analysis}

For each analysis, both enzyme activity and phenotypic differences in mutants were compared with the WT using one-way ANOVA. The P values were derived from post hoc tests using Dunnett's adjustment for multiple comparisons. Statistical analyses were performed with Prism 6 software (GraphPad Software, Inc.).

\section{Availability of supporting data}

The data sets supporting the results of this article are included within the article and its additional files. The accession numbers of the genes analyzed in this study are as follows: GALT1: At1g26810; GALT2: At4g21060; GALT3: At3g06440; GALT4: At1g27120; GALT5: At1g74800; GALT6: At5g62620.

\section{Additional file}

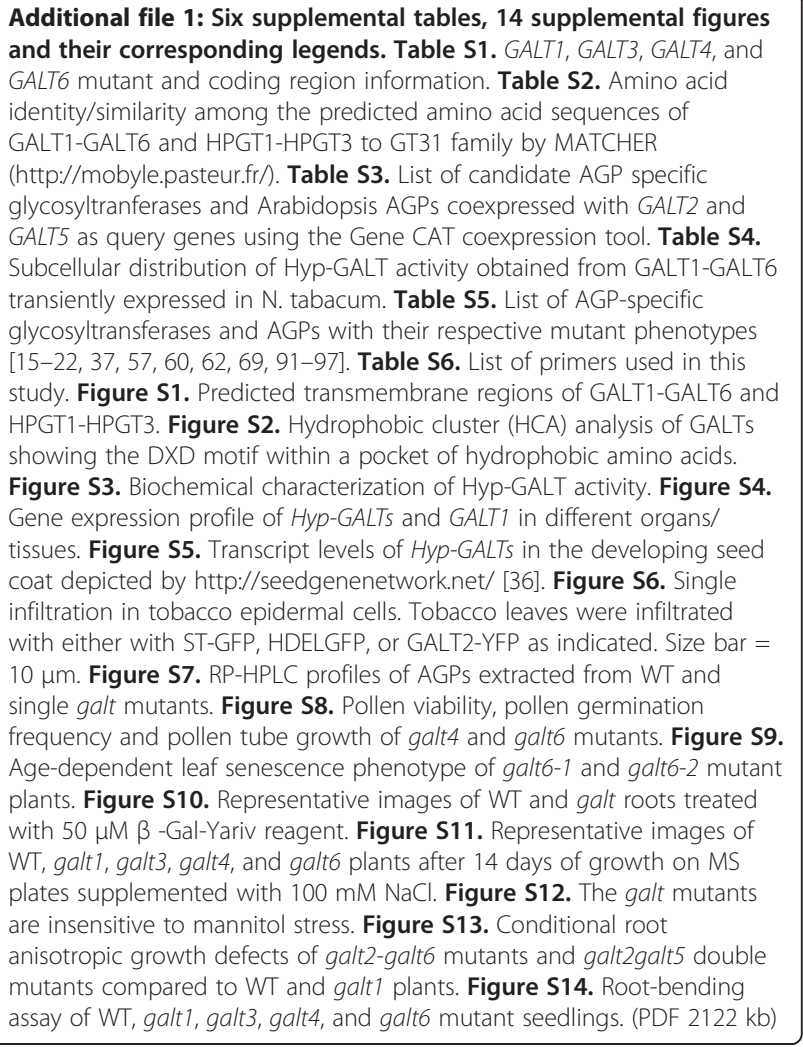

\section{Abbreviations}

AGP: arabinogalactan - protein; CAZy: carbohydrate active enzyme database; GT: glycosyltransferase; HRGP: hydroxyproline-rich glycoprotein;

Hyp: hydroxyproline; Hyp-O-GALT: hydroxyproline-O-galactosyltransferase.

\section{Competing interests}

The authors declare that they have no competing interests.

\section{Authors' contributions}

$\mathrm{LT}, \mathrm{SB}, \mathrm{HH}$, and AT assisted DB in screening homozygous mutants and in performing phenotypic analysis. WW performed cloning of GALT4 and GALT6 for subcellular localization. AMS and DB conceived the study and wrote the manuscript. All authors have read and approved the final version of the manuscript.

\section{Acknowledgments}

We thank Jeff Thuma for his technical assistance in confocal microscopy. This work was supported by a National Science Foundation Grant (grant no. 0918661) and an Ohio University Baker Grant FN1006071.

Received: 20 July 2015 Accepted: 26 November 2015 Published online: 21 December 2015

\section{References}

1. Majewska-Sawka A, Nothnagel EA. The multiple roles of arabinogalactan proteins in plant development. Plant Physiol. 2000;122:3-10.

2. Showalter AM, Keppler B, Lichtenberg J, Gu D, Welch LR. A bioinformatics approach to the identification, classification, and analysis of hydroxyprolinerich glycoproteins. Plant Physiol. 2010;153:485-513.

3. Ma H, Zhao J. Genome-wide identification, classification, and expression analysis of the arabinogalactan protein gene family in rice (Oryza sativa L.). J Exp Bot. 2010;61:2647-68.

4. Seifert GJ, Roberts K. The biology of arabinogalactan proteins. Annu Rev Plant Biol. 2007;58:137-61. 
5. Ellis M, Egelund J, Schultz CJ, Bacic A. Arabinogalactan proteins: key regulators at the cell surface? Plant Physiol. 2010;153:403-19.

6. Tan L, Showalter AM, Egelund J, Hernandez-Sanchez A, Doblin MS, Bacic A Arabinogalactan-proteins and the research challenges for these enigmatic plant cell surface proteoglycans. Front Plant Sci. 2012;3:1-10.

7. Tan L, Eberhard S, Pattathil S, Warder C, Glushka J, Yuan C, et al. An Arabidopsis cell wall proteoglycan consists of pectin and arabinoxylan covalently linked to an arabinogalactan protein. Plant Cell. 2013;25:270-87.

8. Pereira AM, Pereira LG, Coimbra S. Arabinogalactan proteins: rising attention from plant biologists. Plant Reprod. 2015;28:1-15.

9. Nguema-Ona E, Coimbra S, Vicré-Gibouin M, Mollet JC, Driouich A. Arabinogalactan proteins in root and pollen-tube cells: distribution and functional aspects. Ann Bot. 2012;110:383-404

10. Seifert GJ, Xue $H$, Acet T. The Arabidopsis thaliana FASCICLIN LIKE ARABINOGALACTAN PROTEIN 4 gene acts synergistically with abscisic acid signaling to control root growth. Ann Bot. 2014;114:1125-33.

11. Knoch E, Dilokpimol A, Geshi N. Arabinogalactan proteins: focus on carbohydrate active enzymes. Front Plant Sci. 2014;11:198.

12. Wu YY, Williams M, Bernard S, Driouich A, Showalter AM, Faik A. Functional identification of two nonredundant Arabidopsis a $(1,2)$ fucosyltransferases specific to arabinogalactan proteins. J Biol Chem. 2010;285:13638-45.

13. Liang $Y$, Basu D, Pattathil S, Xu W-L, Venetos A, Martin SL, et al. Biochemical and physiological characterization of fut4 and fut6 mutants defective in arabinogalactan-protein fucosylation in Arabidopsis. J Exp Bot. 2013:64:5537-51.

14. Tryfona T, Theys TE, Wagner T, Stott K, Keegstra K, Dupree P. Characterisation of FUT4 and FUT6 $\mathrm{a}-(1 \rightarrow 2)$-fucosyltransferases reveals that absence of root arabinogalactan fucosylation increases Arabidopsis root growth salt sensitivity. PLoS ONE. 2014;9:Article ID e93291.

15. Basu D, Liang Y, Liu X, Himmeldirk K, Faik A, Kieliszewski M, et al. Functional identification of a hydroxyproline-O-galactosyltransferase specific for arabinogalactan protein biosynthesis in Arabidopsis. J Biol Chem. 2013;288:10132-43.

16. Basu D, Wang W, Ma S, DeBrosse T, Poirier E, Emch K, et al. Two hydroxyproline galactosyltransferases, GALT5 and GALT2, function in arabinogalactan-protein glycosylation, growth and development in Arabidopsis. PLOS ONE. 2015;10:Article ID e0125624.

17. Ogawa-Ohnishi M, Matsubayashi Y. Identification of three potent hydroxyproline O-galactosyltransferases in Arabidopsis. Plant J. 2015;81:736-46.

18. Qu Y, Egelund J, Gilson PR, Houghton F, Gleeson PA, Schultz CJ, et al. Identification of a novel group of putative Arabidopsis thaliana $\beta-(1,3)$ galactosyl transferases. Plant Mol Biol. 2008;68:43-59.

19. Geshi N, Johansen JN, Dilokpimol A, Rolland A, Belcram K, Verger S, et al. A galactosyltransferase acting on arabinogalactan protein glycans is essential for embryo development in Arabidopsis. Plant J. 2013;76:128-37.

20. Dilokpimol A, Poulsen CP, Vereb G, Kaneko S, Schulz A, Geshi N. Galactosyltransferases from Arabidopsis thaliana in the biosynthesis of type II arabinogalactan:molecular interaction enhances enzyme activity. BMC Plant Biol. 2014;14:90.

21. Knoch E, Dilokpimol A, Tryfona T, Poulsen CP, Xiong G, Harholt J, et al. A $\beta$-glucuronosyltransferase from Arabidopsis thaliana involved in biosynthesis of type II arabinogalactan has a role in cell elongation during seedling growth. Plant J. 2013;76:1016-29.

22. Dilokpimol A, Geshi N. Arabidopsis thaliana glucuronosyltransferase in family GT14. Plant Signal Behav. 2014;9:e28891.

23. Gille S, Sharma V, Baidoo EEK, Keasling JD, Scheller HV, Pauly M. Arabinosylation of a Yariv-precipitable cell wall polymer impacts plant growth as exemplified by the Arabidopsis glycosyltransferase mutant ray1. Mol Plant. 2013;6:1369-72.

24. Strasser R, Bondili JS, Vavra U, Schoberer J, Svoboda B, Glossl J, et al. A unique $\beta-1,3$-galactosyltransferase is indispensable for the biosynthesis of $\mathrm{N}$-glycans containing Lewis a structures in Arabidopsis thaliana. Plant Cell. 2007;19:2278-92

25. Emanuelsson $\mathrm{O}$, Brunak $\mathrm{S}$, von Heijne $\mathrm{G}$, Nielsen $\mathrm{H}$. Locating proteins in the cell using TargetP, SignalP and related tools. Nat Protoc. 2007;2:953-71.

26. Krogh A, Larsson B, von Heijne G, Sonnhammer EL. Predicting transmembrane protein topology with a hidden Markov model. Application to complete genomes. J Mol Biol. 2001;305:567-80.

27. Callebaut I, Labesse G, Durand P, Poupon A, Canard L, Chomilier J, et al. Deciphering protein sequence information through hydrophobic cluster analysis (HCA): current status and perspectives. Cell Mol Life Sci. 1997;53:621-45.
28. Stolz J, Munro S. The components of the Saccharomyces cerevisiae mannosyltransferase complex M-Pol I have distinct functions in mannan synthesis. J Biol Chem. 2002;277:44801-8.

29. Mostafavi S, Ray D, Warde-Farley D, Grouios C, Morris QD. GeneMANIA: a real-time multiple association network integration algorithm for predicitng gene function. Genome Biol. 2008;9:S4.

30. Zimmermann P, Hirsch-Hoffmann M, Hennig L, Gruissem W. GENEVESTIGATOR. Arabidopsis microarray database and analysis toolbox. Plant Physiol. 2004;136:2621-32.

31. Tetsuya H. Peptide signaling in pollen-pistil interactions. Plant Cell Physiol. 2010;51:177-89.

32. Cheung AY, Wu H-M. Structural and signaling networks for the polar cell growth machinery in pollen tubes. Annu Rev Plant Biol. 2008;59: 547-72.

33. Suárez C, Zienkiewicz A, Castro AJ, Zienkiewicz K, Majewska-Sawka A Rodríguez-García MI. Cellular localization and levels of pectins and arabinogalactan proteins in olive (Olea europaea L.) pistil tissues during development: implications for pollen-pistil interaction. Planta. 2013;237: 305-19.

34. Winter D, Vinegar B, Nahal H, Ammar R, Wilson GV, Provart NJ. An 'electronic fluorescent pictograph' browser for exploring and analyzing large-scale biological data sets. PLoS ONE. 2007;2:Article ID e718.

35. Qin Y, Leydon AR, Manziello A, Pandey R, Mount D, Denic S, et al. Penetration of the stigma and style elicits a novel transcriptome in pollen tubes, pointing to genes critical for growth in a pistil. PLoS Genet. 2009;5:Article ID e1000621.

36. Le BH, Cheng C, Bui AQ, Wagmaister JA, Henry KF, Pelletier J, et al. Global analysis of gene activity during Arabidopsis seed development and identification of seed-specific transcription factors. Proc Natl Acad Sci U S A. 2010;107:8063-70

37. Harpaz-Saad S, McFarlane HE, Xu S, Divi UK, Forward B, Western TL, et al Cellulose synthesis via the FEI2 RLK/SOS5 pathway and CELLULOSE SYNTHASE 5 is required for the structure of seed coat mucilage in Arabidopsis. Plant J. 2011;68:941-53.

38. Griffiths JS, Tsai AY, Xue H, Voiniciuc C, Sola K, Seifert G, et al. SALTOVERLY SENSITIVE5 mediates Arabidopsis seed coat mucilage adherence and organization through pectins. Plant Physiol. 2014;165:991-1004.

39. Koornneef $M$. The complex syndrome of the ttg mutants. Arabidopsis Inf Serv. 1981;18:45-51.

40. Arsovski AA, Haughn GW, Western TL. Seed coat mucilage cells of Arabidopsis thaliana as a model for plant cell wall research. Plant Signal Behav. 2010;5:796-801.

41. Huang J, DeBowles D, Esfandiari E, Dean G, Carpita NC, Haughn GW. The Arabidopsis transcription factor LUH/MUM1 is required for extrusion of seed coat mucilage. Plant Physiol. 2011;156:491-502.

42. Egelund J, Ellis MA, Doblin MS, Qu Y, Bacic A. Genes and enzymes of the GT31 family: towards unraveling the function(s) of the plant glycosyltransferase family members. In: Plant Polysaccharides: Biosynthesis and Bioengineering, editor, Ulvskov P. Oxford: WileyBlackwell; 2011;213-234.

43. Kieliszewski MJ, O’Neill M, Leykam J, Orlando R. Tandem mass-spectrometry and structural elucidation of glycopeptides from a hydroxyproline-rich plant-cell wall glycoprotein indicate that contiguous hydroxyproline residues are the major sites of hydroxyproline O-arabinosylation. J Biol Chem. 1995;270:2541-9.

44. Kieliszewski MJ, Shpak E. Synthetic genes for the elucidation of glycosylation codes for arabinogalactan-proteins and other hydroxyproline-rich glycoproteins. Cell Mol Life Sci. 2001;58:1386-98.

45. Liang Y, Faik A, Kieliszewski M, Tan L, Xu WL, Showalter AM. Identification and characterization of in vitro galactosyltransferase activities involved in arabinogalactan protein glycosylation in tobacco and Arabidopsis. Plant Physiol. 2010;154:632-42.

46. Oka T, Saito F, Shimma Y, Yoko-o T, Nomura Y, Matsuoka K, et al. Characterization of endoplasmic reticulum-localized UDP-D-galactose. Hydroxyproline O-galactosyltransferase using synthetic peptide substrates in Arabidopsis. Plant Physiol. 2010;152:332-40.

47. Gardiner M, Chrispeels MJ. Involvement of the Golgi apparatus in the synthesis and secretion of hydroxyproline-rich cell wall glycoproteins. Plant Physiol. 1975;55:536-41.

48. Robinson DG, Glas R. Secretion kinetics of hydroxyproline-containing macromolecules in carrot root discs. Plant Cell Rep. 1982;5:197-8. 
49. Nikolovski N, Rubtsov D, Segura MP, Miles GP, Stevens TJ, Dunkley TP, et al. Putative glycosyltransferases and other plant Golgi apparatus proteins are revealed by LOPIT proteomics. Plant Physiol. 2012;160:1037-51.

50. Savage N, Yang TJW, Chen CY, Lin K-L, Monk NAM, Schmidt W. Positional signaling and expression of ENHANCER of TRY and CPC1 are tuned to increase root hair density in response to phosphate deficiency in Arabidopsis thaliana. PLOS ONE. 2013;8(10):e75452.

51. Singh SK, Fischer $U$, Singh $M$, Grebe M, Marchant A. Insight into the early steps of root hair formation revealed by the procuste1 cellulose synthase mutant of Arabidopsis thaliana. BMC Plant Biol. 2008;8:57. doi:10.1186/1471-2229-8-57.

52. Baumberger N, Doesseger B, Guyot R, Diet A, Parsons RL, Clark MA, et al. Whole-genome comparison of leucine-rich repeat extensins in Arabidopsis and rice: a conserved family of cell wall proteins form a vegetative and a reproductive clade. Plant Physiol. 2003;131:1313-26.

53. Marzec M, Szarejko I, Melzer M. Arabinogalactan proteins are involved in root hair development in barley. J Exp Bot. 2015;66:1245-57.

54. Velasquez SM, Ricardi MM, Dorosz JG, Fernandez PV, Nadra AD, Pol-Fachin L. O-glycosylated cell wall proteins are essential in root hair growth. Science. 2011;332:1401-3.

55. Velasquez SM, Ricardi MM, Poulsen CP, Oikawa A, Dilokpimol A, Halim A et al. Complex regulation of prolyl-4-hydroxylases impacts root hair expansion. Mol Plant. 2015:8:734-46.

56. Jia QS, Zhu Z, Xu XF, Yue L, Zhang ZL, Zhang ZP, et al. Arabidopsis AT-hook protein TEK positively regulates the expression of arabinogalactan proteins for nexine formation. Mol Plant. 2015;8:251-60.

57. Coimbra S, Costa M, Mendes MA, Pereira AM, Pinto J, Pereira LG. Early germination of Arabidopsis pollen in a double null mutant for the arabinogalactan protein genes AGP6 and AGP11. Sexual Plant Reprod. 2010;23:199-205.

58. Cheung AY, Wang H, Wu HM. A floral transmitting tissue-specific glycoprotein attracts pollen tubes and stimulates their growth. Cell. 1995;82:383-93.

59. Levitin B, Richter D, Markovich I, Zik M. Arabinogalactan proteins 6 and 11 are required for stamen and pollen function in Arabidopsis. Plant J. 2008;56:351-63.

60. Coimbra S, Costa M, Jones B, Mendes MA, Pereira L. G Pollen grain development is compromised in Arabidopsis agp6 agp11 null mutants. J Exp Bot. 2009;60:3133-42

61. Acosta-Garcia G, Vielle-Calzada JP. A classical arabinogalactan protein is essential for the initiation of female gametogenesis in Arabidopsis. Plant Cell. 2004;16:2614-28.

62. Acosta-Garcia G, Vielle-Calzada JP. A classical arabinogalactan protein is essential for the initiation of female gametogenesis in Arabidopsis. Plant Cell. 2004;16:2614-28.

63. Moreau C, Aksenov N, Lorenzo MG, Segerman B, Funk C, Nilsson P, et al. A genomic approach to investigate developmental cell death in woody tissues of Populus trees. Genome Biol. 2005;6:R34.

64. Schindler T, Bergfeld R, Schopfer P. Arabinogalactan proteins in maize coleoptiles: developmental relationship to cell death during xylem differentiation but not to extension growth. Planta. 1995;183:139-42.

65. Gao MG, Showalter AM. Immunolocalization of LeAGP-1, a modular arabinogalactan-protein, reveals its developmentally regulated expression in tomato. Planta. 2000;210:865-74.

66. Chaves I, Regalado AP, Chen M, Ricardo CP, Showalter AM. Programmed cell death induced by ( $\beta$-D-galactosyl) ${ }_{3}$ Yariv reagent in Nicotiana tabacum BY-2 suspension-cultured cells. Physiol Plant. 2002;116:548-53.

67. Sun W, Kieliszewski MJ, Showalter AM. Overexpression of tomato LeAGP-1 arabinogalactan-protein promotes lateral branching and hampers reproductive development. Plant J. 2004;40:870-81.

68. Willats WGT, Knox JP. A role for arabinogalactan-proteins in plant cell expansion: evidence from studies on the interaction of beta-glucosyl Yariv reagent with seedlings of Arabidopsis thaliana. Plant J. 1996;9:919-25.

69. Mollet JC, Kim S, Jauh GY, Lord EM. Arabinogalactan proteins, pollen tube growth, and the reversible effects of Yariv phenylglycoside. Protoplasma. 2002;219:89-98.

70. Nguema-Ona E, Bannigan A, Chevalier L, Baskin TI, Driouich A. Disruption of arabinogalactan-proteins disorganizes cortical microtubules in the root of Arabidopsis thaliana. Plant J. 2007;52:240-51.

71. Nguema-Ona E, Moore JP, Fagerström A, Fangel JU, Willats WGT, Hugo A, et al. Profiling the main cell wall polysaccharides of tobacco leaves using high throughput techniques. Carbohydr Polym. 2012;88:939-49.
72. Xu SL, Rahman A, Baskin TI, Kieber JJ. Two leucine-rich repeat receptor kinases mediate signaling, linking cell wall biosynthesis and ACC synthase in Arabidopsis. Plant Cell. 2008;20:3065-79.

73. Shi H, Kim Y, Guo Y, Stevenson B, Zhu J-K. The Arabidopsis SOS5 locus encodes a putative cell surface adhesion protein and is required for normal cell expansion. Plant Cell. 2003;15:19-32.

74. Nielsen H, Brunak S, von Heijne G. Machine learning approaches to the prediction of signal peptides and other protein sorting signal (review). Protein Eng. 1999;12:3-9.

75. Breton C, Bettler E, Joziasse DH, Geremia RA, Imberty A. Sequence-function relationships of prokaryotic and eukaryotic galactosyltransferases. J Biochem (Tokyo). 1998;123:1000-9.

76. Murray MG, Thompson WF. Rapid isolation of high molecular weight plant DNA. Nucleic Acids Res. 1980;8:4321-5.

77. Boyes DC, Zayed AM, Ascenzi R, McCaskill AJ, Hoffman NE, Davis KR, et al. Growth stage-based phenotypic analysis of Arabidopsis: a model for high throughput functional genomics in plants. Plant Cell. 2001;13: 1499-510

78. Schultz CJ, Johnson KL, Currie G, Bacic A. The classical arabinogalactan protein gene family of Arabidopsis. Plant Cell. 2000;12:1751-67.

79. Gao M, Kieliszewski MJ, Lamport DT, Showalter AM. Isolation, characterization, and immunolocalization of a novel, modular tomato arabinogalactan protein corresponding to the LeAGP-1 gene. Plant J. 1999;18:43-55.

80. Yariv J, Lis $H$, Katchalski E. Precipitation of arabic acid and some seed polysaccharides by glycosylphenylazo dyes. J Biochem. 1967;105:1C-2C.

81. Youl JJ, Bacic A, Oxley D. Arabinogalactan-proteins from Nicotiana alata and Pyrus communis contain glycosylphosphatidylinositol membrane anchors. Proc Natl Acad Sci U S A. 1998:95:7921-6.

82. Lamport DTA, Várnai P. Periplasmic arabinogalactan glycoproteins act as a calcium capacitor that regulates plant growth and development. New Phytol. 2013;197:58-64.

83. Zhu J-K, Liu J, Xiong L. Genetic analysis of salt tolerance in Arabidopsis. Evidence for a critical role of potassium nutrition. Plant Cell. 1998;10:1181-91.

84. Boavida L, McCormick S. Temperature as a determinant factor for increased and reproducible in vitro pollen germination in Arabidopsis thaliana. Plant J. 2007;52:570-82.

85. Willats WGT, McCartney L, Knox JP. In-situ analysis of pectic polysaccharides in seed mucilage and at the root surface of Arabidopsis thaliana. Planta. 2001;213:37-44.

86. Yu L, Shi D, Li J, Kong Y, Yu Y, Chai G, et al. CELLULOSE SYNTHASE-LIKE A2, a glucomannan synthase, is involved in maintaining adherent mucilage structure in Arabidopsis seed. Plant Physiol. 2014;164:1842-56.

87. Alexander MP. Differential staining of aborted and nonaborted pollen. Stain Technol. 1969:44:117-22.

88. Breeze E, Harrison E, McHattie S, Hughes L, Hickman R, Hill C, et al. Highresolution temporal profiling of transcripts during Arabidopsis leaf senescence reveals a distinct chronology of processes and regulation. Plant Cell. 2011;23:873-94.

89. Xiao S, Dai LY, Liu FQ, Wang ZL, Peng W, Xie DX. COS1: An Arabidopsis coronatine insensitive1 suppressor essential for regulation of jasmonatemediated plant senescence and defense. Plant Cell. 2004;16:1132-42.

90. Dubois M, Gilled K, Hamilton JK, Rebers PA, Smith F. Colorimetric method for the determination of sugars and related substances. Anal Chem. 1956;28:350-6.

91. Li J, Yu M, Geng LL, Zhao J. The fasciclin-like arabinogalactan protein gene, FLA3, is involved in microspore development of Arabidopsis. Plant J. 2010;64:482-97.

92. Johnson KL, Kibble NAJ, Bacic A, Schultz CJ. A fasciclin-like arabinogalactanprotein FLA mutant of Arabidopsis thaliana, fla1, shows defects in shoot regeneration. PLOS ONE. 2011;6:e25154.

93. MacMillan CP, Mansfield SD, Stachurski ZH, Evans R, Southerton SG. Fasciclin-like arabinogalactan proteins: specialization for stem biomechanics and cell wall architecture in Arabidopsis and Eucalyptus. Plant J. 2010;62:689-703.

94. Yang J, Sardar HS, McGovern KR, Zhang YZ, Showalter AM. A lysine-rich arabinogalactan protein in Arabidopsis is essential for plant growth and development, including cell division and expansion. Plant J. 2007;49: 629-40.

95. Gaspar YM, Nam J, Schultz CJ, Lee LY, Gilson PR, Gelvin SB, et al. Characterization of the Arabidopsis lysine-rich arabinogalctan protein 
AtAGP17 mutant (rat1) that results in a decreased efficiency of Agrobacterium transformation. Plant Physiol. 2004;135:2162-71.

96. Demesa-Arévalo E, Vielle-Calzada JP. The classical arabinogalactan protein AGP18 mediates megaspore selection in Arabidopsis. Plant Cell. 2013;25: 1274-87.

97. van Hengel AJ, Roberts K. Fucosylated arabinogalactan-proteins are required for full root cell elongation in Arabidopsis. Plant J. 2002;32:105-13.

Submit your next manuscript to BioMed Central and we will help you at every step:

- We accept pre-submission inquiries

- Our selector tool helps you to find the most relevant journal

- We provide round the clock customer support

- Convenient online submission

- Thorough peer review

- Inclusion in PubMed and all major indexing services

- Maximum visibility for your research 